\title{
Low-Voltage Heterojunction Metal Oxide Transistors via Rapid Photonic Processing
}

Emre Yarali, Hendrik Faber, Emre Yengel, Akmaral Seitkhan, Kalaivanan Loganathan, George T. Harrison, Begimai Adilbekova, Yuanbao Lin, Chun Ma, Yuliar Firdaus, Thomas D. Anthopoulos*

E. Yarali, Dr. H. Faber, Dr. E. Yengel, A. Seitkhan, K. Loganathan, A. Seitkhan, Dr. G. T. Harrison, B. Adilbekova, Y. Lin, C. Ma, Dr. Y. Firdaus, Prof. T. D. Anthopoulos

King Abdullah University of Science and Technology (KAUST),

KAUST Solar Center (KSC), Thuwal 23955, Saudi Arabia.

Email: thomas.anthopoulos@kaust.edu.sa

Keywords: Photonic curing, metal oxide semiconductors, metal oxide dielectrics, thin-film transistors, metal oxide heterojunctions

\begin{abstract}
Solution-processed metal oxide thin-film transistors (TFTs) represent a promising technology for applications in existing but also emerging large-area electronics. However, high process temperatures and lengthy annealing times represent two remaining challenges. Different approaches aiming to address these challenges have been proposed but progress remains modest. Here, we describe the development of high electron mobility metal oxide TFTs based on photonically converted $\mathrm{Al}_{2} \mathrm{O}_{3} / \mathrm{ZrO}_{2}$ and $\mathrm{In}_{2} \mathrm{O}_{3} / \mathrm{ZnO}$ bilayers acting as the high- $k$ dielectric and electron-transporting channel, respectively. Sequential solution-phase deposition and photonic processing lead to low substrate temperature $\left(<200{ }^{\circ} \mathrm{C}\right)$ while minimizing the overall process time to less than $60 \mathrm{~s}$ without compromising the quality of the formed layers. The bilayer $\mathrm{Al}_{2} \mathrm{O}_{3} / \mathrm{ZrO}_{2}$ dielectric exhibits low leakage current density $\left(10^{-6} \mathrm{~A} \mathrm{~cm}^{-2}\right.$ at $\left.1 \mathrm{MV} \mathrm{cm}^{-1}\right)$, high geometric capacitance $\left(\approx 120 \mathrm{nF} \mathrm{cm} \mathrm{cm}^{-2}\right)$ and breakdown electric field of $\approx 1 \mathrm{MV} \mathrm{cm}^{-1}$. Combining $\mathrm{Al}_{2} \mathrm{O}_{3} / \mathrm{ZrO}_{2}$ with a photonically converted $\mathrm{In}_{2} \mathrm{O}_{3} / \mathrm{ZnO}$ heterojunction channels, results in TFTs with high electron mobility $\left(19 \mathrm{~cm}^{2} \mathrm{~V}^{-1} \mathrm{~s}^{-1}\right)$, low operation voltage $(\leq 2 \mathrm{~V})$, high current on/off ratio $\left(>10^{6}\right)$, and low subthreshold swing $\left(108 \mathrm{mV} \mathrm{dec}^{-1}\right)$, that can be manufactured even onto thermally sensitive polymer substrates. The work is a significant step towards all-photonic processed metal oxide electronics.
\end{abstract}




\section{Introduction}

Ongoing technological and product developments provide the driving force towards thin-film transistors (TFTs) technologies with improved performance characteristics and manufacturability. Since their debut as channel materials in TFTs, ${ }^{[1]}$ metal oxide semiconductors have quickly become the subject of intense research due to their outstanding electrical and optical properties. ${ }^{[2-4]}$ There are various methods that can be used to grow metal oxide semiconductors the most common of which is via gas phase techniques such as physical vapor deposition (PVD) ${ }^{[5]}$ chemical vapor deposition (CVD) ${ }^{[6]}$ and atomic layer deposition (ALD). ${ }^{[7]}$ However, solution-based manufacturing techniques promise several advantages such as higher throughput and easier scalability for a range of envisioned inexpensive large-area electronic applications. ${ }^{[8,9]}$

To reach comparable performance to vacuum-processed metal oxide TFTs, solutionprocessed oxides typically rely on high-temperature thermal annealing $\left(>400{ }^{\circ} \mathrm{C}\right)$ over long time scales (hours). Not only does this step increase the process time and energy consumption, but it also restricts the choice of substrate materials. For these reasons, alternative methods have been explored. ${ }^{[9,10]}$ Among those, new chemical routes using, for example, nitrate-based precursors $^{[11]}$, combustion synthesis ${ }^{[12]}$ or novel post-annealing techniques such as UVprocessing, plasma or microwave treatments have been investigated ${ }^{[13-15]}$ for both dielectric and semiconductor metal oxide materials. Although significant improvements have been made to decrease the fabrication temperatures and process times, still only a few methods satisfy these requirements.

Photonic sintering is a post-processing method that has recently been attracting increasing attention as an alternative to conventional thermal annealing. ${ }^{[16-18]}$ In its simplest form, short pulses ( $\mu$ s to ms) of high-intensity white light (broad spectrum of 200-1100 nm) generated by a xenon flash lamp are directed towards the substrate. Absorption of the light by the material(s) deposited on the substrate (metals or functional materials) can result in a 
dramatic increase of the temperature to over $1000{ }^{\circ} \mathrm{C}$ for a short period of time that is comparable to the pulse duration. Most importantly, during the process, the substrate remains at low temperatures due to the short light exposure time and the mismatches of thermal equilibrium times of the absorber and the substrate materials. ${ }^{[17]}$ Although material combinations with different thermal expansion coefficients can lead to thermomechanical stress formation during the process, this can be mitigated by adequately tuning the process parameters (optical power density, number of shape of flashes and the frequency of optical pulses). Indeed, due to its fast and large area processing capability, the flash light annealing technique was already demonstrated for roll-to-roll (R2R) fabrication, specifically for the conversion of metal inks into highly conductive patterns. ${ }^{[16,19]}$ Apart from metal inks, a particular advantage of photonic curing over other low-temperature processing techniques is that it provides a significantly faster conversion from the precursor solution into solid thin layers while very high temperatures are localized only on the surface of the absorber element for the solution-based thin film fabrication. The rapid nature of the photonic process and its compatibility with a broad range of inexpensive substrate materials, such as a range of polymers, makes it an appealing fabrication method for high throughput manufacturing.

Here we report the rapid manufacturing of solution-processed, low operating voltage metal oxide TFTs where the dielectric and the semiconducting channels are both processed via photonic processing in ambient atmosphere. Within the group of metal oxide-based dielectrics, $\mathrm{ZrO}_{2}$ and $\mathrm{Al}_{2} \mathrm{O}_{3}$ are well studied materials. While $\mathrm{ZrO}_{2}$ has a higher permittivity (25) than $\mathrm{Al}_{2} \mathrm{O}_{3}$ (9), its lower band gap (5.8vs. 9 for $\mathrm{Al}_{2} \mathrm{O}_{3}$ ) can result in higher leakage currents, especially for thin-films. ${ }^{[20]}$ To mitigate this problem and simultaneously achieve a high capacitance, the usage of homo- or heterojunction bilayer dielectric layers was suggested. ${ }^{[21,22]} \mathrm{We}$ adopted a similar approach and explored the use of $\mathrm{Al}_{2} \mathrm{O}_{3} / \mathrm{ZrO}_{2}$ bilayer dielectric layers. The bilayer gate dielectric of $\mathrm{Al}_{2} \mathrm{O}_{3} / \mathrm{ZrO}_{2}$ was first grown on aluminum ( $\mathrm{Al}$ ) gate electrodes via sequential spin coating and flash annealing (for a duration of $16 \mathrm{~s}$ ). Using the same steps, a low-dimensional 
channel comprising an $\mathrm{In}_{2} \mathrm{O}_{3} / \mathrm{ZnO}$ heterojunction, ${ }^{[23]}$ was then grown atop the $\mathrm{Al}_{2} \mathrm{O}_{3} / \mathrm{ZrO}_{2}$ dielectric. This specific combination of materials and stacking sequence for the active channel, i.e. $\mathrm{In}_{2} \mathrm{O}_{3} / \mathrm{ZnO}$, was chosen based on multiple previous studies showing the enhanced properties compared to single layer channels. ${ }^{[23-26]}$

Structural and electrical analysis of the $\mathrm{Al}_{2} \mathrm{O}_{3} / \mathrm{ZrO}_{2}$ dielectric reveals the presence of a bilayer structure that exhibits low leakage current $\left(10^{-6} \mathrm{~A} \mathrm{~cm}^{-2}\right)$, high breakdown field $(\approx 1 \mathrm{MV}$ $\left.\mathrm{cm}^{-1}\right)$, smooth surface roughness $(0.43 \mathrm{~nm})$ and high geometrical capacitance $\left(\approx 120 \mathrm{nF} \mathrm{cm} \mathrm{cm}^{-2}\right)$. As-prepared $\operatorname{In}_{2} \mathrm{O}_{3} / \mathrm{ZnO}$ heterojunction TFTs exhibit n-channel characteristics with low voltage operation $( \pm 2 \mathrm{~V})$ and high electron mobility $\left(19 \mathrm{~cm}^{2} \mathrm{~V}^{-1} \mathrm{~s}^{-1}\right)$; an effect attributed to the formation of quasi-two-dimensional electron gas (q-2DEG) confined at the $\operatorname{In}_{2} \mathrm{O}_{3} / \mathrm{ZnO}$ interface. The presence of a q2DEG was corroborated experimentally via carrier profiling capacitance-voltage $(\mathrm{C}-\mathrm{V})$ measurements.

\section{Results and discussion}

\subsection{Photonic curing of metal oxide layers}

Figure 1 depicts the fabrication steps used to fabricate the metal oxide TFTs. A bottom-gate, top-contact transistor configuration was employed and combined with bilayer $\mathrm{Al}_{2} \mathrm{O}_{3} / \mathrm{ZrO}_{2}$ dielectric ${ }^{[21]}$ and high mobility heterojunction $\mathrm{In}_{2} \mathrm{O}_{3} / \mathrm{ZnO}^{[4]}$ channels. During photonic treatment the $\mathrm{Al}$ layer plays a dual role, first acting as the gate electrode and secondly as the light absorber which heats-up and converts the precursor layer deposited on top of it. ${ }^{[23]}$ In brief, device fabrication (Figure 1) starts with the spin casting of the desired precursor solution followed by a drying step (step 1). Next, the sample is placed in close proximity to the xenon lamp (step 2) and subjected to pulse(s) of light of varying intensity and duration (see Experimental). During illumination, the gate electrode absorbs part of the light which raises the temperature of its surface rapidly whilst the substrate remains significantly cooler. The sample is then left to cool for a few seconds at room temperature (step 3). Under optimal processing 
conditions, the precursor layer deposited atop the Al electrode converts fully to the thermally stable metal oxide phase. Steps 1 to 3 can be repeated numerous times allowing for accurate control of the stoichiometry and layer thickness of the multilayer oxides.

During photonic processing of the $\mathrm{Al}_{2} \mathrm{O}_{3}$ layer, we observed a strong correlation between the $\mathrm{Al}$ thickness and the optimal molarity of the aluminum oxide precursor formulation used. Non-optimized conditions led to $\mathrm{Al}$ electrode delamination (ablation) and the formation of partially destroyed gate-dielectric structures. Table S1 and Figure S1 (Supporting Information) summarize the effect of electrode thickness and molarity of the precursor formulation processed at a constant illumination intensity. The results reveal that use of a higher molarity $\mathrm{Al}\left(\mathrm{NO}_{3}\right)_{3} \cdot 9 \mathrm{H}_{2} \mathrm{O}$ precursor formulation in combination with thinner $\mathrm{Al}$ gate electrodes leads to pronounced gate ablation (Figure S1). Table 1 summarizes the materials and the corresponding processing conditions used to successfully convert the different precursors to the targeted metal oxides.

Table 1. Summary of the energy, pulse duration and the number of pulses used for the different metal oxides. For all oxide layers, the fire rate was kept at $1.2 \mathrm{~Hz}$ and the applied voltage 600 V.

\begin{tabular}{lccc}
\hline Material & $\begin{array}{c}\text { Energy density } \\
\left(\mathrm{J} \mathrm{cm}^{-2}\right)\end{array}$ & $\begin{array}{c}\text { Pulse length } \\
(\mu \mathrm{s})\end{array}$ & Number of pulses \\
\hline $\mathrm{Al}_{2} \mathrm{O}_{3}$ & 1.84 & 250 & 20 \\
$\mathrm{ZrO}_{2}$ & 1.84 & 250 & 20 \\
$\mathrm{In}_{2} \mathrm{O}_{3}$ & 4.44 & 600 & 30 \\
$\mathrm{ZnO}$ & 4.44 & 600 & 10 \\
\hline
\end{tabular}

The SimPulse software tool was used to simulate the temperature evolution on the aluminum electrode surface (Figure 2). ${ }^{[27]}$ Due to the mismatch of thermal conductivities between $\mathrm{Al}$ and the glass substrate, the supplied optical energies are sufficient to increase the 
temperature of $\mathrm{Al}$ while maintaining the substrate temperature low. For the growth of the dielectric layers on $\mathrm{Al}$, the simulations suggest that temperatures $>500{ }^{\circ} \mathrm{C}$ can easily be reached within $16 \mathrm{~s}$ (20 pulses) with the substrate temperature remaining $<120^{\circ} \mathrm{C}$ (Figure $2 \mathbf{a}$ and $2 \mathbf{b}$ ). Considering the time scale of the process and the low substrate temperature, the fabrication conditions appear to be compatible with temperature-sensitive substrate materials such as plastics. ${ }^{[3]}$ Interestingly, Figure $2 \mathrm{c}$ shows that the $\mathrm{ZrO}_{2}$ surface can momentarily reach temperatures in excess of $1000{ }^{\circ} \mathrm{C}$ within $25 \mathrm{~s}$. In the latter case, however, the substrate temperature increases as well reaching $300{ }^{\circ} \mathrm{C}$. These results highlight the effectiveness of the xenon flash lamp to rapidly deliver energy to thin $\mathrm{Al}$ electrodes that act as micro-hotplates. Even though the same xenon lamp-driving voltage and pulse length were used to process the $\mathrm{ZnO}$ layer, a lower number of pulses was required to reach sufficiently high conversion temperatures, owing to its different optical properties and precursor chemistry ${ }^{[21]}$ (Figure 2d).

Thermogravimetric analysis (TGA) was used to study the decomposition temperatures of the various precursors. With the exception of $\mathrm{ZnO}$, all precursors show dehydroxylation and condensation at $\geq 250{ }^{\circ} \mathrm{C}$ (Figure S2). No such transition is observed for $\mathrm{ZnO}$ due to the specific chemistry employed. These results together with the SimPulse simulations, suggest that the temperatures required for dehydroxylation and condensation of the metal oxide precursors can easily be reached during photonic processing.

X-ray photoelectron spectroscopy (XPS) was used to monitor the degree of chemical conversion of the individual oxides before and after photonic treatment by studying the evolution of the O 1s spectra (see Figure S3 a-d and Table S2). The dominant peak between 531.5 and $530.5 \mathrm{eV}$ is attributed to metal-oxygen-metal bonds, ${ }^{[28,29]}$ while the $2^{\text {nd }}$ and $3^{\text {rd }}$ peaks can be assigned to hydroxide and nitrate groups inside the thin film, respectively. ${ }^{[30]}$ As spun films dried at $130{ }^{\circ} \mathrm{C}$ show higher amounts of hydroxide groups in $\mathrm{Al}_{2} \mathrm{O}_{3}$, and both hydroxide and nitrate for $\mathrm{In}_{2} \mathrm{O}_{3}$ layers, respectively. Upon flashing all oxide precursor layers show reduced intensities in the corresponding $\mathrm{M}-\mathrm{OH}$ and $\mathrm{O}-\mathrm{NO}_{3}$ peaks accompanied by increased $\mathrm{M}-\mathrm{O}$ signal 
intensities. Even though relatively high amounts of hydroxide groups may be observed right after the flashing of individual layers, these values will be lowered due to further processing of subsequent layers atop.

\subsection{Photonic processing of multilayer metal oxide dielectrics}

The use of high band-gap materials as gate dielectrics in transistors is beneficial due to low leakage currents. $\mathrm{Al}_{2} \mathrm{O}_{3}$ is a widely used gate dielectric in metal oxide TFTs as it combines a high band gap $(\approx 9 \mathrm{eV})^{[20]}$ with abundance and processing versatility. Unfortunately, its relatively low dielectric constant $(k=9)$ leads to lower geometrical capacitance as compared to other high- $k$ metal oxides such as $\mathrm{ZrO}_{2}$ and $\mathrm{HfO}_{2} \cdot \mathrm{ZrO}_{2}$, in particular, has been attracting increasing attention in recent years due to its processing simplicity and very high relative permittivity $(\kappa=25) \cdot{ }^{[31,32]}$ However, its relatively small band gap $(\approx 5.8 \mathrm{eV})$ often results in higher leakage currents and adverse effects on device performance. A simple approach to overcome this issue is by using multilayer dielectrics. ${ }^{[2,33,34]}$ Figure 3a shows a set of currentvoltage $(J-V)$ characteristics for metal/insulator/metal (MIM) devices based on photonically converted $\mathrm{Al}_{2} \mathrm{O}_{3} / \mathrm{ZrO}_{2}$ bilayer as the dielectric. All devices show similar $J$ - $V$ characteristics with low leakage currents $\left(<10^{-5} \mathrm{~A} \mathrm{~cm}^{-2}\right)$ and breakdown fields in the range $0.8-1 \mathrm{MV} \mathrm{cm}^{-1}$. The fluctuations seen in the latter are attributed to non-uniformities associated with the $\mathrm{Al}_{2} \mathrm{O}_{3}$ layer and will be discussed later. ${ }^{[35]}$ In comparison with $\mathrm{Al}_{2} \mathrm{O}_{3} / \mathrm{ZrO}_{2}$ bilayer dielectric, the single layers of $\mathrm{Al}_{2} \mathrm{O}_{3}$ and $\mathrm{ZrO}_{2}$ showed high leakage current densities (see Figure S4). Because of this it was deemed unsuitable for application on its own.

Capacitance-voltage (C-V) and capacitance-frequency (C-f) measurements performed on the same MIM structure reveal a high capacitance value of $\approx 118 \mathrm{nF} \mathrm{cm}^{-2}$ (Figure $3 \mathbf{b}$ ) which remains stable with respect to the applied voltage and increasing frequency up to $7 \mathrm{MHz}$ (Figure 3c). We attribute the good dielectric properties to the successful precursor decomposition and layer densification during photonic treatment. To verify this hypothesis we 
examined the surface topography of all photonically processed layers via intermittent atomic force microscopy (AFM). Figure 4 shows AFM images of the surface topographies for the various layers measured after deposition. Bare aluminum (Figure 4a) exhibits a relatively rough surface with a root mean square roughness $\left(\sigma_{\mathrm{RMS}}\right)$ of $1.81 \mathrm{~nm}$, which is common for thermally evaporated $\mathrm{Al}^{\left[{ }^{[22]}\right.}$ The surface of the photonically converted $\mathrm{Al}_{2} \mathrm{O}_{3}$ layer appears amorphous and retains a relatively high surface roughness of $\sigma_{\mathrm{RMS}}=1.6 \mathrm{~nm}($ Figure $4 \mathbf{b})$. Subsequently deposited $\mathrm{ZrO}_{2}$, on the other hand (Figure 4c), exhibits significantly smoother surface with a drastically reduced $\sigma_{\mathrm{RMS}}$ of $0.43 \mathrm{~nm}$. The positive effect of channel interface planarization was investigated in our previous study ${ }^{[22]}$ and is critical for the formation of a well-defined transistor channel. Figures $4 \mathbf{d}$ and $\mathbf{4 e}$ show the topography AFM images for the photonically processed $\mathrm{In}_{2} \mathrm{O}_{3}$ and $\mathrm{ZnO}$ layers, respectively, atop the bilayer dielectric. $\operatorname{In}_{2} \mathrm{O}_{3}$ exhibits a smooth surface with $\sigma_{\mathrm{RMS}}=1.07 \mathrm{~nm}$ as compared to $\mathrm{ZnO}\left(\sigma_{\mathrm{RMS}}=1.85 \mathrm{~nm}\right)$. These findings are in agreement with previous reports on $\mathrm{ZnO}$, which always revealed the presence of a strongly textured surface. ${ }^{[23,26]}$ The differences in the AFM topographies between the various photonically processed layers are clearer in the height histogram of Figure $\mathbf{4 f}$.

The electron transport in single-layer $\operatorname{In}_{2} \mathrm{O}_{3}$ and $\mathrm{ZnO}$ transistors as well as in $\operatorname{In}_{2} \mathrm{O}_{3} / \mathrm{ZnO}$ heterojunction transistors, was studied in a bottom-gate, top-contact (BG-TC) device architecture. Figure 5a-c show sets of the corresponding transfer characteristics. All TFTs exhibit $n$-channel behavior and operate at low voltages in the range -0.5 to $2 \mathrm{~V}$. Gate leakage currents at maximum $\mathrm{V}_{\mathrm{G}}$ were on the order of $100 \mathrm{nA}$ or below in all cases. While $\mathrm{ZnO}$ and $\mathrm{In}_{2} \mathrm{O}_{3} / \mathrm{ZnO}$ devices show negligible hysteresis, this is not the case for $\operatorname{In}_{2} \mathrm{O}_{3}$ TFTs. We attribute this to charge trapping at states located in the $\operatorname{In}_{2} \mathrm{O}_{3}$ surface, which can be filled or passivated when $\mathrm{ZnO}$ is deposited atop in a subsequent step. The threshold voltage $\left(\mathrm{V}_{\mathrm{T}}\right)$ of each devices is also different with the lowest value of $0.5 \mathrm{~V}$ measured for the $\mathrm{In}_{2} \mathrm{O}_{3} / \mathrm{ZnO}$ TFT (Figure 5d), which also indicates a higher electron density in the channel. ${ }^{[26,36,37]}$ 
Folowing the growth of the $\mathrm{Al}_{2} \mathrm{O}_{3} / \mathrm{ZrO}_{2}$ bilayer dielectric, deposition of the single layer of $\mathrm{In}_{2} \mathrm{O}_{3}$ was optimized by tuning the energy density of the flash light while keeping the pulse length and number of flashes constant (Figure S5a). The resulting $\operatorname{In}_{2} \mathrm{O}_{3}$ TFTs exhibit an electron saturation mobility value of $5.7 \mathrm{~cm}^{2} \mathrm{~V}^{-1} \mathrm{~s}^{-1}$ which is significantly higher than $\mathrm{ZnO}$ transistors $\left(1 \mathrm{~cm}^{2} \mathrm{~V}^{-1} \mathrm{~s}^{-1}\right)$. The relatively low mobilities are attributed to structural and/or chemical defects present in the channel ${ }^{[38]}$ and are comparable with values reported previously for solution-processed TFTs prepared via thermal annealing. ${ }^{[34]}$

Optimization of the operating characteristics of the $\operatorname{In}_{2} \mathrm{O}_{3} / \mathrm{ZnO}$ devices, on the other hand, was achieved by tuning the number of pulses while keeping the energy density of flashes and pulse length constant during the processing $\mathrm{ZnO}$ (Figure S5b). Resulting $\operatorname{In}_{2} \mathrm{O}_{3} / \mathrm{ZnO}$ TFTs exhibit a significantly higher mobility of up to $19 \mathrm{~cm}^{2} \mathrm{~V}^{-1} \mathrm{~s}^{-1}$; that is $>3 \times$ higher than singlelayer $\mathrm{In}_{2} \mathrm{O}_{3}$ and $19 \times$ higher than $\mathrm{ZnO}$ devices. The higher electron mobility and lower $\mathrm{V}_{\mathrm{T}}$ are consistent with the existence of a q-2DEG confined at the $\operatorname{In}_{2} \mathrm{O}_{3} / \mathrm{ZnO}$ heterointerface in agreement with previous reports. ${ }^{[26,36,39]}$ Moreover, $\operatorname{In}_{2} \mathrm{O}_{3} / \mathrm{ZnO}$ TFTs exhibit a high channel current on/off ratio of $1.4 \times 10^{6}$ and a subthreshold swing of $108 \mathrm{mV} / \mathrm{dec}$. Furthermore, the output characteristics of the TFTs exhibit good saturation with no signs of injection barriers (Figure 5e).

To better understand the origin of the higher electron mobility in $\operatorname{In}_{2} \mathrm{O}_{3} / \mathrm{ZnO}$ TFTs, we measured the electron concentration as a function of depth across the heterojunction channel using C-V measurements. Figure 6a shows the C-V characteristics measured for a metalinsulator-semiconductor (MIS) capacitor where both electron accumulation and depletion regimes can be identified. ${ }^{[36]}$ From the $\mathrm{C}-\mathrm{V}$ characteristics, it is possible to study the distribution apparent electron concentration $\left(\mathrm{N}_{\mathrm{C}-\mathrm{V}}\right)$ across the channel using previously published methods. ${ }^{[36]}$ Figure $6 \mathbf{b}$ shows the $\mathrm{N}_{\mathrm{C}-\mathrm{V}}$ versus channel layer depth with zero distance representing the position of the top semiconductor-Al electrode interface. ${ }^{[40]}$ Evidently, $\mathrm{N}_{\mathrm{C}-\mathrm{V}}$ shows a distinct peak at $\approx 4 \mathrm{~nm}$ from the channel interface, which correlates well with the 
expected location of the $\mathrm{In}_{2} \mathrm{O}_{3} / \mathrm{ZnO}$ heterointerface. Although the shape of the peak in $\mathrm{N}_{\mathrm{C}-\mathrm{V}}$ would be expected to be very sharp for an atomically-flat interface, its broader nature indicates the existence of interface roughness. This observation agrees with the surface height histograms shown in Figure 4f, which show that the topography of $\mathrm{ZnO}$ and $\operatorname{In}_{2} \mathrm{O}_{3}$ fluctuate between 4 and $6 \mathrm{~nm}$. Considering the low-dimensionality of the heterojunction channel, the these results can be considered to be in good agreement. Overall, electrical characterization of the $\operatorname{In}_{2} \mathrm{O}_{3} / \mathrm{ZnO}$ TFTs provides direct evidence of a highly anisotropic distribution of electrons in the out-ofplane direction of the heterojunction channel corroborating the existence of a q-2DEG at the critical heterointerface (see Figure S6). ${ }^{[26]}$

To gain further insights into the nature of the $\mathrm{In}_{2} \mathrm{O}_{3} / \mathrm{ZnO}$ heterojunction formed via sequential solution-processing and photonic sintering, we performed cross-sectional highresolution transmission electron microscopy (HRTEM). Figure 7a shows the cross-sectional HRTEM image of the channel region, where the various layers can be discerned. Regions of the $\mathrm{Al}$ gate electrode appear to have melted and recrystallized during photonic processing as clearly visible in Figure 7a. The total thickness of the $\mathrm{Al}_{2} \mathrm{O}_{3} / \mathrm{ZrO}_{2}$ bilayer is around $30 \mathrm{~nm}$, while that of the $\mathrm{In}_{2} \mathrm{O}_{3} / \mathrm{ZnO}$ heterojunction channel varies between 13-18 $\mathrm{nm}$ (Figure 7b). Combining scanning TEM (STEM) and electron energy loss spectroscopy (EELS) analysis (Figure 7c) allows the demarcation of the various metal oxide layer (i.e. $\mathrm{Al}_{2} \mathrm{O}_{3}, \mathrm{ZrO}_{2}, \mathrm{In}_{2} \mathrm{O}_{3}$, $\mathrm{ZnO}$ ). $\mathrm{Al}_{2} \mathrm{O}_{3}$ and $\mathrm{ZrO}_{2}$ appear to be $\approx 25$ and $\approx 4 \mathrm{~nm}$-thick, respectively, with some evidence of intermixing. On the other hand, the $\mathrm{In}_{2} \mathrm{O}_{3}$ and $\mathrm{ZnO}$ layers are $\approx 5$ and $\approx 8 \mathrm{~nm}$, respectively (Figure 7b). Possible reasons why the individual layers/interfaces are not clearly distinguishable, as compared to previous reports, ${ }^{[26]}$ is the high surface roughness of the underlying material (e.g., evaporated $\mathrm{Al}$ gate electrodes $v s . \mathrm{SiO}_{2}$ ), and/or the rapid nature of the chemical conversion occurring upon photonic processing. Despite that, however, the EELS data in Figure 7c provide direct evidence of the existence of discrete oxide layers with the expected 
elemental compositional order i.e., $\mathrm{Al}, \mathrm{Zr}$, In and $\mathrm{Zn}$, with oxygen $(\mathrm{O})$ being present throughout the multilayer structure.

To demonstrate the compatibility of photonic processing with temperature-sensitive substrates, we fabricated $\operatorname{In}_{2} \mathrm{O}_{3} / \mathrm{ZnO}$ heterojunction TFTs on the bilayer high- $k$ dielectric, on polyethylene naphthalate (PEN) substrates without using any thermal buffer layer. Due to the different thermal properties of PEN to those of glass, the possible thermal stress is more pronounced given the same flashing parameters. This problem could be overcome by inserting a buffer layer, such as $\mathrm{SiO}_{2}$ or polyimide $(\mathrm{PI}),{ }^{[30]}$ between substrate and metal or the tuning of flashing parameters for the temperature sensitive substrates. However, the insertion of such buffer layer increases fabrication complexity as it requires an extra fabrication step and for this reason it was not pursued here. Instead, a lower optical energy density of $1.1 \mathrm{~J} \mathrm{~cm}^{-2}$ and 60 pulses (2 ms pulse length) at a fire rate of $0.1 \mathrm{~Hz}$, were employed (Figure S7). Figure 8a-b shows the transfer characteristics and a photograph of the $\operatorname{In}_{2} \mathrm{O}_{3} / \mathrm{ZnO}$ heterojunction transistor arrays based on $\mathrm{Al}_{2} \mathrm{O}_{3} / \mathrm{ZrO}_{2}$ dielectric fabricated on flexible PEN substrate, respectively. The transistors exhibit a maximum electron mobility of $2.3 \mathrm{~cm}^{2} \mathrm{~V}^{-1} \mathrm{~s}^{-1}$, threshold voltage of $0.86 \mathrm{~V}$, subthreshold swing $(S S)$ of $123 \mathrm{mV}$ and channel $\mathrm{IoN} / \mathrm{IOFF}$ ratio of $\approx 10^{5}$. The difference in performance between TFTs fabricated on glass and PEN substrates is most likely attributed to the different temperature gradients formed on the surface of the aluminum gate electrode and the increased surface roughness introduced by the PEN substrate as compared to the much smoother glass surface. One important difference is that in the case of glass, significantly higher optical energy intensities can be used without damaging the substrate due to its higher thermal conductivity. This, however, is not the case for PEN due to its lower thermal conductivity. As such, the maximum attainable device performance is limited by the mismatch in the thermal properties between the absorber (i.e. Al electrode in this case) and the substrate materials. 


\section{Conclusions}

We have demonstrated the ability to rapidly manufacture high electron mobility $\operatorname{In}_{2} \mathrm{O}_{3} / \mathrm{ZnO}$ heterojunction transistors using the high- $k$ bilayer dielectric $\mathrm{Al}_{2} \mathrm{O}_{3} / \mathrm{ZrO}_{2}$ via photonic processing over glass and flexible substrates. We achieved this using a patterned $\mathrm{Al}$ electrode acting simultaneously as the gate and optical energy absorber that thermally converts the spincast metal oxide precursor deposited atop to the targeted metal oxide. Unlike conventional thermal annealing, photonic processing occurs at ultra-short time scales -milliseconds to seconds as compared to tens of minutes- without adverse effects on the transistor characteristics. Importantly, the photothermally induced precursor conversion can be repeated many times allowing for sequential deposition of different materials on a variety of substrates, including temperature-sensitive polymers. Heterojunction $\operatorname{In}_{2} \mathrm{O}_{3} / \mathrm{ZnO}$ TFTs utilizing the high$k$ bilayer dielectric $\mathrm{Al}_{2} \mathrm{O}_{3} / \mathrm{ZrO}_{2}$ were shown to exhibit electron mobility values up to $19 \mathrm{~cm}^{2} \mathrm{~V}^{-}$ ${ }^{1} \mathrm{~s}^{-1}$ when compared to TFTs made with single-layer $\operatorname{In}_{2} \mathrm{O}_{3}\left(5.7 \mathrm{~cm}^{2} \mathrm{~V}^{-1} \mathrm{~s}^{-1}\right)$ and $\mathrm{ZnO}\left(1 \mathrm{~cm}^{2} \mathrm{~V}^{-1}\right.$ $\mathrm{s}^{-1}$ ). Finally, the same $\mathrm{Al} / \mathrm{Al}_{2} \mathrm{O}_{3} / \mathrm{ZrO}_{2} / \mathrm{In}_{2} \mathrm{O}_{3} / \mathrm{ZnO}$-based TFTs were fabricated on PEN substrates, further showcasing the potential of photonic processing as a method for large-area manufacturing of future oxide electronics over arbitrary substrate materials.

\section{Experimental Section}

Precursor preparation: For the deposition of $\mathrm{Al}_{2} \mathrm{O}_{3}, \mathrm{ZrO}_{2}$ and $\mathrm{In}_{2} \mathrm{O}_{3}$, 2-methoxyethanol solutions containing aluminum nitrate nonahydrate $\left(\mathrm{Al}\left(\mathrm{NO}_{3}\right)_{3} \cdot 9 \mathrm{H}_{2} \mathrm{O}, 98 \%\right.$ Sigma-Aldrich), zirconium acetylacetonate $\left(\mathrm{Zr}\left(\mathrm{C}_{5} \mathrm{H}_{7} \mathrm{O}_{2}\right)_{4}, 99 \%\right.$ Sigma-Aldrich $)$ and indium nitrate $\left(\operatorname{In}\left(\mathrm{NO}_{3}\right)_{3}\right.$, 99.99\%; Indium Corporation) at concentrations of 100, 25 and $20 \mathrm{mg} \mathrm{mL}^{-1}$, respectively, were employed. The solutions were subjected to $60{ }^{\circ} \mathrm{C}$ heating with vigorous stirring overnight before use. The $\mathrm{ZnO}$ precursor was prepared by dissolving $\mathrm{ZnO}$ hydrate $\left(\mathrm{ZnO} \cdot \mathrm{xH}_{2} \mathrm{O}, 97 \%\right.$; Sigma-Aldrich) in ammonium hydroxide (50\% v/v; Alfa Aesar) at a concentration of $7 \mathrm{mg} \mathrm{mL}^{-}$ ${ }^{1}$ at room temperature and stirring overnight. 
Transistor Fabrication: Borofloat glass of $1.1 \mathrm{~mm}$ thickness was used as the substrate material for device fabrication. Glass substrates were cleaned by ultrasonication in DI water, acetone and isopropanol for $10 \mathrm{~min}$ each and dried in a nitrogen stream. As the final step of cleaning, a UV/ozone treatment was applied for 5 minutes to remove any residual organic from the surface. Thermally evaporated $100 \mathrm{~nm}$-thick Al was used as combined gate electrodes and as the light absorber element for the photonic curing of dielectric and semiconductor layers that were sequentially deposited atop. The electrode was deposited by thermal evaporation at the rate of $2 \mathrm{~nm} \mathrm{~s}^{-1}$ under a high vacuum of $<10^{-6}$ torr. Prior to spin casting of the metal oxide solutions, Al electrodes were UV/ozone treated to enhance the wettability. All metal oxide precursors were spin-coated at $4000 \mathrm{rpm}$ for $30 \mathrm{~s}$. For the fabrication of dielectric, spin casting of precursor solutions for $\mathrm{Al}_{2} \mathrm{O}_{3}$ and $\mathrm{ZrO}_{2}$ was repeated 5 times for each material in order to increase the overall layer thickness. After deposition, the films were baked at $130{ }^{\circ} \mathrm{C}$ for 6 min to drive out the solvent. Next, the photonic curing step(s) was applied to the dried samples using a Novacentrix Pulse Forge 1300 system. The temperature distribution over the Al surface was simulated using their SimPulse ${ }^{[27]}$ software. The flashing conditions for $\mathrm{Al}_{2} \mathrm{O}_{3}$ and $\mathrm{ZrO}_{2}$ dielectric layers were as follows: optical energy of $1.84 \mathrm{~J} \mathrm{~cm}^{-2}$, pulse length of $250 \mu \mathrm{s}$ and the number of pulses was kept to 20. Following the deposition of the gate dielectric, an $\operatorname{In}_{2} \mathrm{O}_{3}$ layer was spin-cast inside a nitrogen atmosphere. The as-cast precursor layer was first dried at $130{ }^{\circ} \mathrm{C}$ for 6 min and then flashed with 30 pulses using optical energy of $4.44 \mathrm{~J} \mathrm{~cm}^{-2}$ with a pulse length of $600 \mu \mathrm{s}$. For the $\mathrm{ZnO}$ layer, spin-coating was conducted in ambient environment and the film was dried at $110{ }^{\circ} \mathrm{C}$ for 6 min. Dry $\mathrm{ZnO}$ layers were then subjected to 10 pulses of the same energy and duration as for the $\operatorname{In}_{2} \mathrm{O}_{3}$ layer. Finally, 40 nm-thick $\mathrm{Al}$ source and drain (S-D) electrodes were deposited via thermal evaporation through a shadow mask. The transistors were electrically characterized in a nitrogen atmosphere using a Keysight B2912A source-meter. The field-effect electron mobility was extracted from the transfer characteristic of the transistors using: 


$$
\mu_{s a t}=\frac{2 L}{W C_{i}}\left(\frac{\partial \sqrt{I_{D(s a t)}}}{\partial V_{G}}\right)^{2}
$$

where $\mathrm{L}$ and $\mathrm{W}$ are the channel length and width, respectively, $\mathrm{C}_{\mathrm{i}}$ is the geometric capacitance of the gate dielectric, $\mathrm{I}_{\mathrm{D} \text { (sat) }}$ is the current in the saturation regime, and $\mathrm{V}_{\mathrm{G}}$ is the gate voltage applied between the gate $(\mathrm{G})$ and the source $(\mathrm{S})$ electrode.

Transistor Fabrication on PEN Substrate: For the fabrication of multilayer transistor over PEN substrate, the same precursor solutions and spin coating parameters were used for all layers as for the glass substrate. Considering the thermal properties of PEN, drying temperature after spin coating was kept $60{ }^{\circ} \mathrm{C}$ for 30 minutes. Differently, the optical energy of $1.1 \mathrm{~J} \mathrm{~cm}^{-2}, 2000 \mu \mathrm{s}$ pulse length, $300 \mathrm{~V}$ and 60 pulses with the fire rate at $0.1 \mathrm{~Hz}$ were used for all the processed layers.

Dielectric characterization: The metal oxide dielectrics were characterized via capacitancevoltage (C-V) measurements using metal-insulator-metal (MIM) and metal-dielectricsemiconductor (MIS) structures with a Keysight B1500A semiconductor parameter analyzer. The capacitance-frequency $(\mathrm{C}-f)$ measurements were carried out at frequencies in the range $10^{3}$ $10^{7} \mathrm{~Hz}$. The leakage current density was evaluated using a MIM structure that was fabricated along the TFTs.

Surface analysis of the deposited layers: Surface roughness and topography of the individual layers were studied by atomic force microscopy (AFM) in tapping mode using a Bruker Dimension Icon with ScanAsyst@. In parallel to AFM analysis, the scanning electron microscopy (SEM) surface images of individual layers were taken with a Carl Zeiss URIGA $^{\circledR}$ CrossBeam ${ }^{\circledR}$ Workstation using in-lens detectors with $5 \mathrm{kV}$ acceleration voltage and $6 \mathrm{~mm}$ working distance.

Transmission electron microscopy: High-resolution transmission electron microscopy (HRTEM) and electron energy loss spectroscopy (EELS) were also employed. Sample preparation was carried out using a Ga focused ion beam (FIB) in a scanning electron 
microscope (SEM) (Helios 400s, FEI) equipped with a nanomanipulator (Omniprobe, AutoProbe300). A thin $2 \mathrm{~nm}$ layer of iridium was sputtered followed by the deposition of carbon and platinum protective layers in the SEM. The sample was then milled with the FIB down to the required thickness. The lamella was then extracted and attached to a copper TEM grid using established protocols. The lamella was thinned down at $30 \mathrm{kV}$ and various currents (2.8-93 pA). At the final stage of the sample preparation, the lamella was cleaned with the ion beam at low voltages $(2-5 \mathrm{kV})$ to remove any contamination. A transmission electron microscopy (Titan 80300, FEI) with $300 \mathrm{kV}$ was used for cross-sectional HRTEM imaging. The EELS elemental map was obtained with Gatan Imaging Filter (GIF) Quantum 966, scanning TEM (STEM). $X$-ray photoemission spectroscopy: XPS measurements were carried out in an MXPS (Omicron) chamber at base pressure of $10^{-9}$ mbar equipped with a X1000 X-ray source (Omicron) and sphera II multi-channeltron analyser (Omicron), in addition a cold cathode ion source (ISE-5, Omicron) was used for preparation of a clean silver surface for calibration. The source was a monochromated $\mathrm{Al} \mathrm{K \alpha} 1486.7 \mathrm{eV}$ at a power of $389.7 \mathrm{~W}(15 \mathrm{kV}, 26 \mathrm{~mA})$ with a source to sample angle of $13^{\circ}$. The photoelectrons were collected from the samples to analyzer angle of $87^{\circ}$ and a tolerance of $7^{\circ}$, at constant pass energy of $15 \mathrm{eV}$ (narrow scans) and $50 \mathrm{eV}$ (survey scans). XPS spectra were analysed in Casa XPS. The spectra binding energy was first calibrated with respect to clean silver $3 \mathrm{~d}$ core line and were calibrated with respect to the adventious carbon $\mathrm{C} 1 \mathrm{~s}$ peak $\approx 284.7 \mathrm{eV}$ to account for surface charging. Fitting of spectra was performed using a Shirley baseline and Gaussian-Lorenzian (GL) spectral function and are presented normalized by area.

Thermogravimetric analysis (TGA): TGA of all precursors was performed using a TGA analyzer (STA $449 \mathrm{~F} 3$ Jupiter from NETZSCH) in the air with a heating rate of $20{ }^{\circ} \mathrm{C} \mathrm{min}^{-1}$. 


\section{Supporting Information}

Supporting Information is available from the Wiley Online Library or from the author.

\section{Acknowledgements}

The authors are grateful to KAUST for the financial support.

Received: ((will be filled in by the editorial staff))

Revised: ((will be filled in by the editorial staff))

Published online: ((will be filled in by the editorial staff))

\section{References}

[1] K. Nomura, Science. 2003, 300, 1269.

[2] E. Fortunato, P. Barquinha, R. Martins, Adv. Mater. 2012, 24, 2945.

[3] L. Petti, N. Münzenrieder, C. Vogt, H. Faber, L. Büthe, G. Cantarella, F. Bottacchi, T.

D. Anthopoulos, G. Tröster, Appl. Phys. Rev. 2016, 3, 021303.

[4] D. Khim, Y.-H. Lin, S. Nam, H. Faber, K. Tetzner, R. Li, Q. Zhang, J. Li, X. Zhang, T. D. Anthopoulos, Adv. Mater. 2017, 29, 1605837.

[5] E. M. C. Fortunato, P. M. C. Barquinha, A. C. M. B. G. Pimentel, A. M. F. Gonçalves, A. J. S. Marques, L. M. N. Pereira, R. F. P. Martins, Adv. Mater. 2005, 17, 590.

[6] Z. Fan, D. Wang, P.-C. Chang, W.-Y. Tseng, J. G. Lu, Appl. Phys. Lett. 2004, 85, 5923.

[7] J. Sheng, T. Hong, H.-M. Lee, K. Kim, M. Sasase, J. Kim, H. Hosono, J.-S. Park, ACS Appl. Mater. Interfaces 2019, 11, 40300.

[8] S. R. Thomas, P. Pattanasattayavong, T. D. Anthopoulos, Chem. Soc. Rev. 2013, 42, 6910.

[9] J. W. Park, B. H. Kang, H. J. Kim, Adv. Funct. Mater. 2019, 1904632, 1904632.

[10] K. K. Banger, Y. Yamashita, K. Mori, R. L. Peterson, T. Leedham, J. Rickard, H. 
Sirringhaus, Nat. Mater. 2011, 10, 45.

[11] A. Liu, G. Liu, H. Zhu, B. Shin, E. Fortunato, R. Martins, F. Shan, $R S C A d v$. 2015, 5, 86606.

[12] M. G. Kim, M. G. Kanatzidis, A. Facchetti, T. J. Marks, Nat. Mater. 2011, 10, 382.

[13] Y.-H. Kim, J.-S. Heo, T.-H. Kim, S. Park, M.-H. Yoon, J. Kim, M. S. Oh, G.-R. Yi, Y.Y. Noh, S. K. Park, Nature 2012, 489, 128.

[14] Y. M. Park, J. Daniel, M. Heeney, A. Salleo, Adv. Mater. 2011, 23, 971.

[15] T. Jun, K. Song, Y. Jeong, K. Woo, D. Kim, C. Bae, J. Moon, J. Mater. Chem. 2011, $21,1102$.

[16] E. Yarali, C. Koutsiaki, H. Faber, K. Tetzner, E. Yengel, P. Patsalas, N. Kalfagiannis, D. C. Koutsogeorgis, T. D. Anthopoulos, Adv. Funct. Mater. 2019, 1906022.

[17] K. A. Schroder, TechConnect Briefs 2011, 2, 220.

[18] K. Tetzner, K. A. Schroder, K. Bock, Ceram. Int. 2014, 40, 15753.

[19] J. Perelaer, R. Abbel, S. Wünscher, R. Jani, T. van Lammeren, U. S. Schubert, Adv. Mater. 2012, 24, 2620.

[20] W. Xu, H. Wang, L. Ye, J. Xu, J. Mater. Chem. C 2014, 2, 5389.

[21] Y. H. Lin, H. Faber, K. Zhao, Q. Wang, A. Amassian, M. McLachlan, T. D. Anthopoulos, Adv. Mater. 2013, 25, 4340.

[22] A. D. Mottram, P. Pattanasattayavong, I. Isakov, G. Wyatt-Moon, H. Faber, Y.-H. Lin, T. D. Anthopoulos, AIP Adv. 2018, 8, 065015.

[23] K. Tetzner, Y.-H. Lin, A. Regoutz, A. Seitkhan, D. J. Payne, T. D. Anthopoulos, J. Mater. Chem. C 2017, 5, 11724.

[24] Y.-H. Lin, W. Li, H. Faber, A. Seitkhan, N. A. Hastas, D. Khim, Q. Zhang, X. Zhang, N. Pliatsikas, L. Tsetseris, P. A. Patsalas, D. D. C. Bradley, W. Huang, T. D. Anthopoulos, Nat. Electron. 2019, 2, 587.

[25] D. Khim, Y. Lin, T. D. Anthopoulos, Adv. Funct. Mater. 2019, 29, 1902591. 
[26] H. Faber, S. Das, Y.-H. Lin, N. Pliatsikas, K. Zhao, T. Kehagias, G. Dimitrakopulos, A. Amassian, P. A. Patsalas, T. D. Anthopoulos, Sci. Adv. 2017, 3, e1602640.

[27] M. J. Guillot, K. A. Schroder, S. C. Mccool, in ASME 2012 International Mechanical Engineering Congress \& Exposition IMECE2012, ASME, New York, USA 2012, pp. $19-27$.

[28] S. Park, K.-H. Kim, J. Jo, S. Sung, K.-T. Kim, W. Lee, J. Kim, H. J. Kim, G. Yi, Y. Kim, M. Yoon, S. K. Park, Adv. Funct. Mater. 2015, 25, 2807.

[29] H. Faber, Y.-H. Lin, S. R. Thomas, K. Zhao, N. Pliatsikas, M. A. McLachlan, A. Amassian, P. A. Patsalas, T. D. Anthopoulos, ACS Appl. Mater. Interfaces 2015, 7, 782.

[30] N. M. Twyman, K. Tetzner, T. D. Anthopoulos, D. J. Payne, A. Regoutz, Appl. Surf. Sci. 2019, 479, 974.

[31] G. Adamopoulos, S. Thomas, P. H. Wöbkenberg, D. D. C. Bradley, M. A. McLachlan, T. D. Anthopoulos, Adv. Mater. 2011, 23, 1894.

[32] S. Park, C.-H. Kim, W.-J. Lee, S. Sung, M.-H. Yoon, Mater. Sci. Eng. R Reports 2017, $114,1$.

[33] J.-W. Jo, K.-H. Kim, J. Kim, S. G. Ban, Y.-H. Kim, S. K. Park, ACS Appl. Mater. Interfaces 2018, 10, 2679.

[34] M. U. Chaudhry, K. Tetzner, Y. H. Lin, S. Nam, C. Pearson, C. Groves, M. C. Petty, T. D. Anthopoulos, D. D. C. Bradley, ACS Appl. Mater. Interfaces 2018, 10, 18445.

[35] A. Liu, H. Zhu, H. Sun, Y. Xu, Y.-Y. Noh, Adv. Mater. 2018, 30, 1706364.

[36] Y. H. Lin, H. Faber, J. G. Labram, E. Stratakis, L. Sygellou, E. Kymakis, N. A. Hastas, R. Li, K. Zhao, A. Amassian, N. D. Treat, M. McLachlan, T. D. Anthopoulos, Adv. Sci. 2015, 2,1 .

[37] M. Lee, J. W. Jo, Y. J. Kim, S. Choi, S. M. Kwon, S. P. Jeon, A. Facchetti, Y. H. Kim, S. K. Park, Adv. Mater. 2018, 30, 1. 
[38] H. Frenzel, A. Lajn, H. Von Wenckstern, M. Lorenz, F. Schein, Z. Zhang, M. Grundmann, Adv. Mater. 2010, 22, 5332.

[39] J. G. Labram, Y. H. Lin, T. D. Anthopoulos, Small 2015, 11, 5472.

[40] S. P. Voinigescu, K. Iniewski, R. Lisak, C. A. T. Salama, J. P. Noél, D. C. Houghton, Solid State Electron. 1994, 37, 1491. 


\section{Figures}
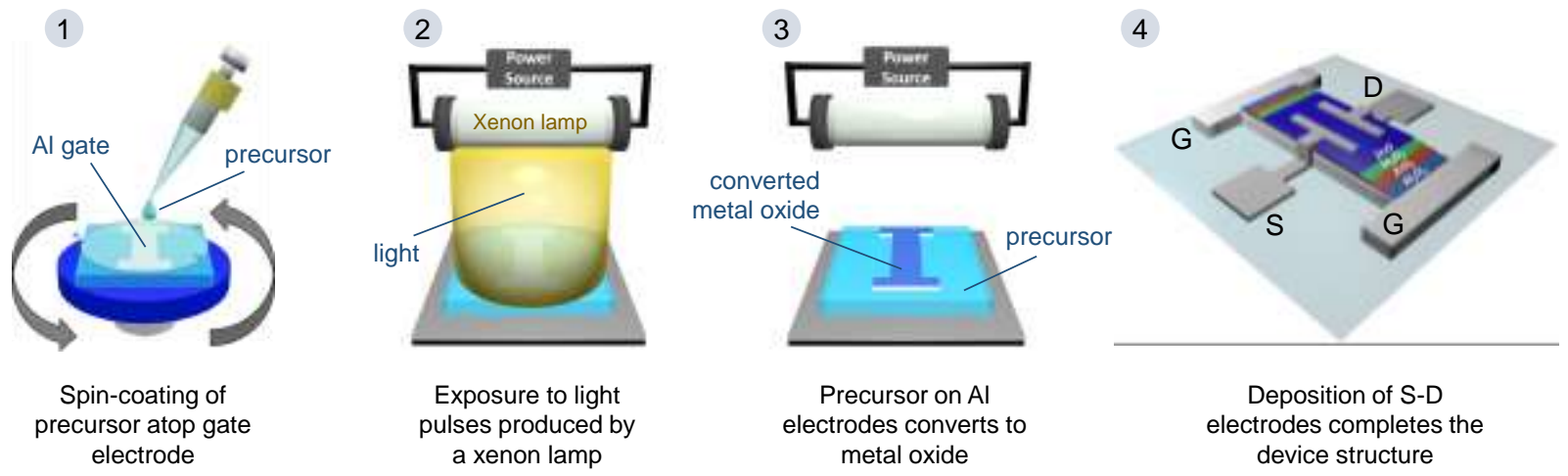

Figure 1. Processing steps used to fabricate metal oxide TFTs via photonic curing. (1) The spin casting of precursor solution onto pre-patterned/deposited Al gate electrodes. (2) Exposure of the sample to high-intensity light pulses generated by a xenon lamp. (3) The precursor film atop the $\mathrm{Al}$ electrode chemically converts to a dense solid oxide layer. (4) Transistor fabrication is completed with the deposition of aluminum (Al) source-drain electrodes via vacuum sublimation. 


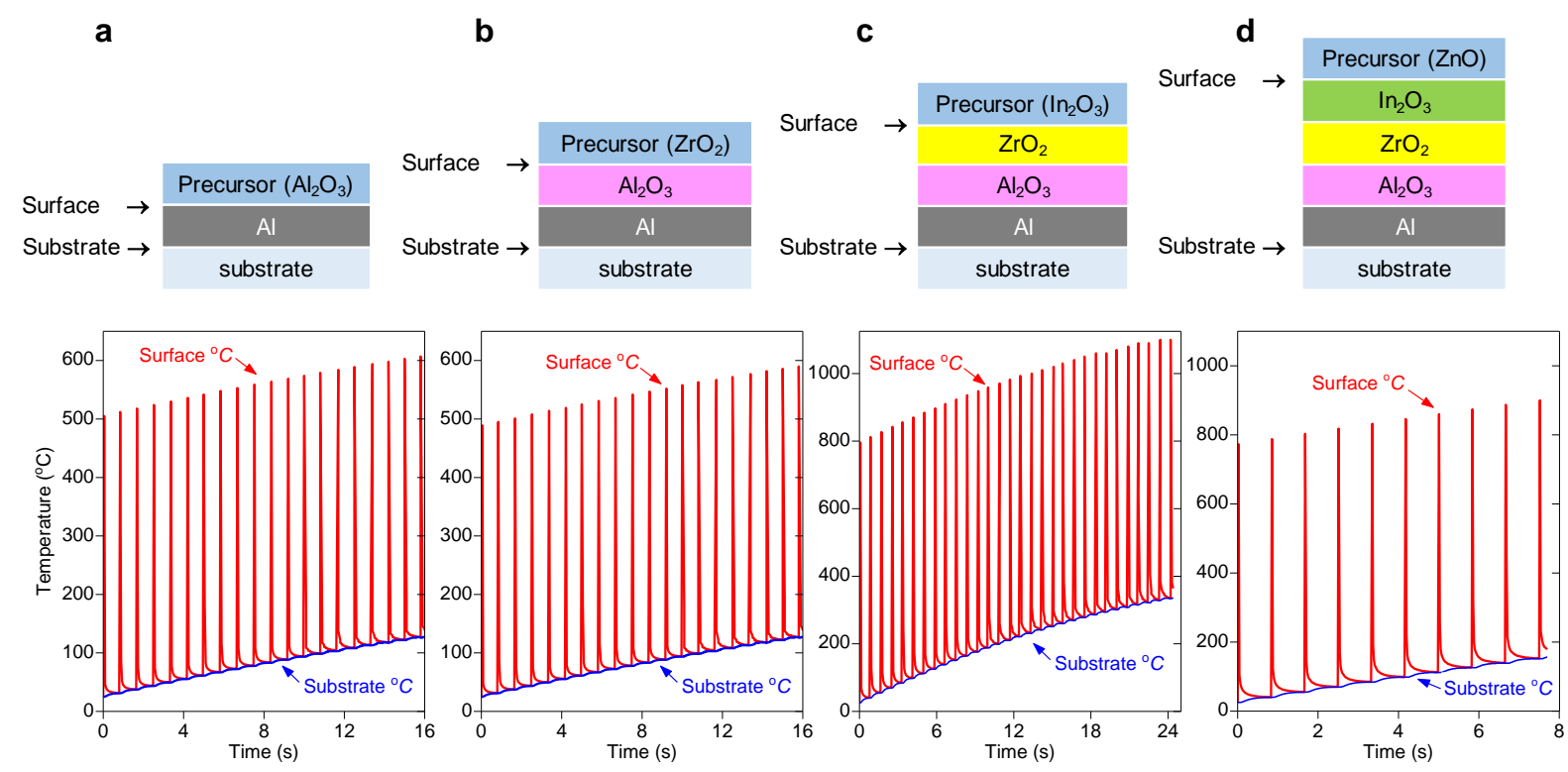

Figure 1. Temperature evolution on the surfaces of $\mathrm{Al}$ electrode (a), $\mathrm{Al}_{2} \mathrm{O}_{3}$ layer (b), $\mathrm{ZrO}_{2}$ layer (c) and $\mathrm{In}_{2} \mathrm{O}_{3}$ layer (d) calculated using the SimPulse software and glass as the substrate material. The results were used as a guide to identify the processing conditions that will lead to successful chemical conversion of the corresponding precursor to the targeted metal oxide, namely $\mathrm{Al}_{2} \mathrm{O}_{3}$ (a), $\mathrm{ZrO}_{2}$ (b) $\mathrm{In}_{2} \mathrm{O}_{3}(\mathrm{c})$, and $\mathrm{ZnO}$ (d). In all cases a fire rate of $1.2 \mathrm{~Hz}$ and $600 \mathrm{~V}$ were used. 

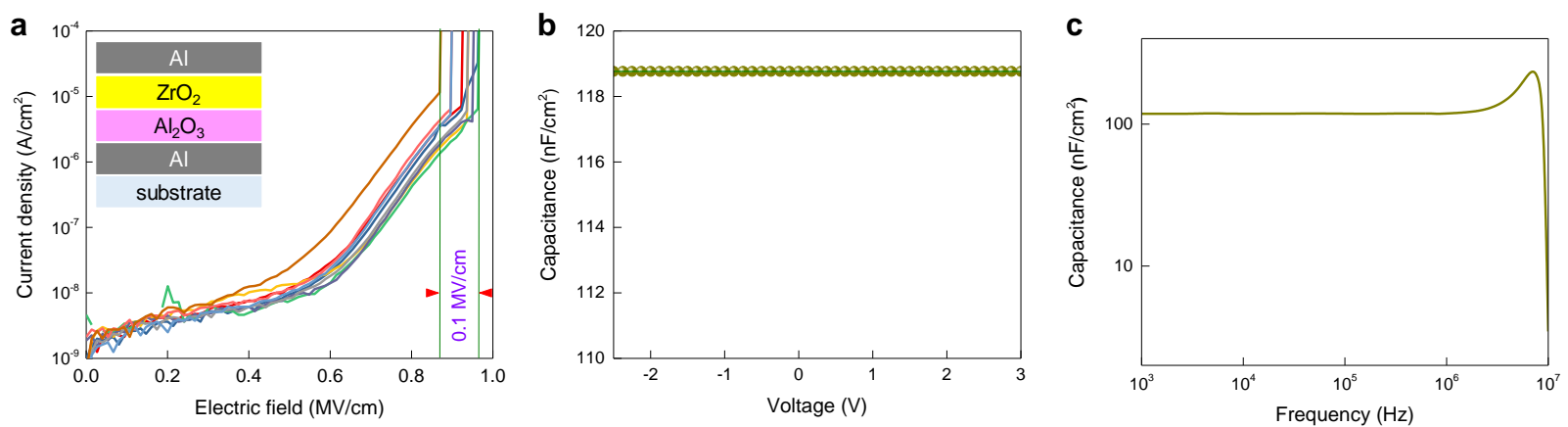

Figure 2. (a) Leakage current density versus applied electric field for a set of similar MIM devices. Inset shows the $\mathrm{Al} / \mathrm{Al}_{2} \mathrm{O}_{3} / \mathrm{ZrO}_{2} / \mathrm{Al}$ device architecture employed. (b) Capacitancevoltage characteristics for a representative $\mathrm{Al} / \mathrm{Al}_{2} \mathrm{O}_{3} / \mathrm{ZrO}_{2} / \mathrm{Al}$ device measured using an $\mathrm{AC}$ signal frequency of $1 \mathrm{kHz}$ with a peak-to-peak voltage of $100 \mathrm{mV}$. (c) Capacitance versus frequency in the range $10^{3}-10^{6} \mathrm{~Hz}$. 


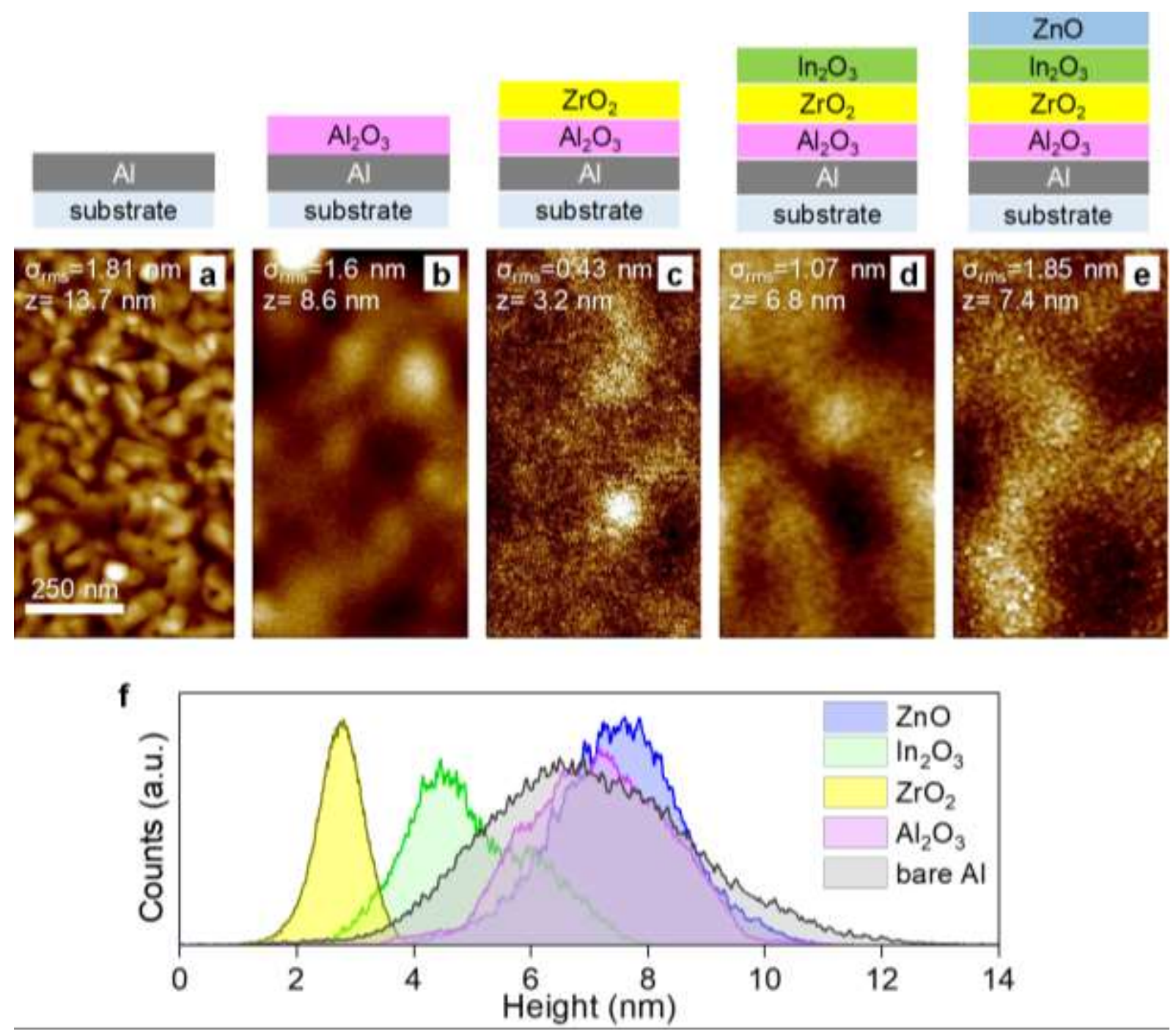

Figure 4. AFM images of the surface topographies of (a) $\mathrm{Al}$ electrode, (b) $\mathrm{Al}_{2} \mathrm{O}_{3}$, (c) $\mathrm{ZrO}_{2}$, (d) $\mathrm{In}_{2} \mathrm{O}_{3}$ (e) $\mathrm{ZnO}$ layers deposited sequentially via spin-coating atop the Al layer and photonically treated at each step. (f) Height histograms of all layers. 

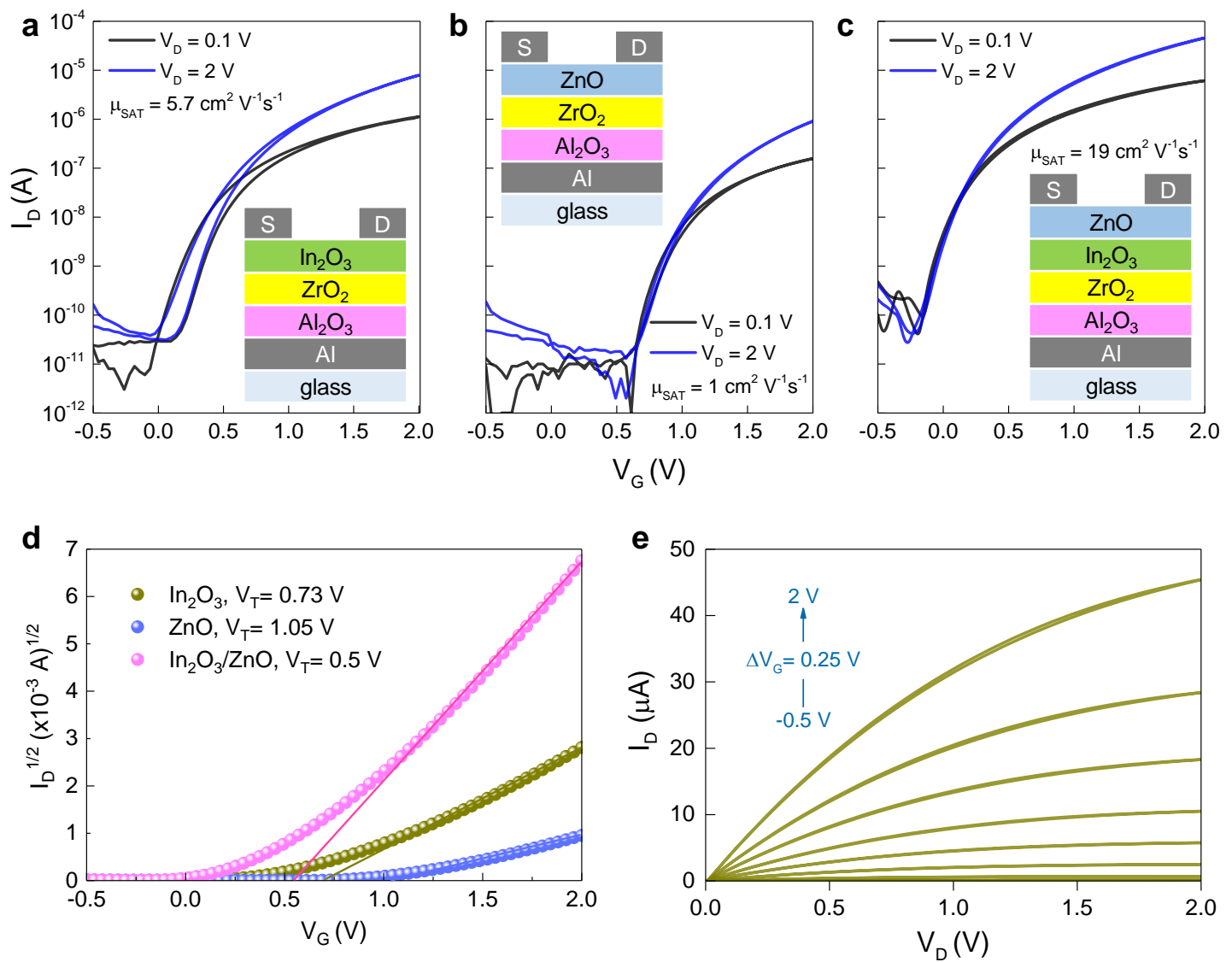

Figure 5. Transfer characteristic of (a) $\mathrm{In}_{2} \mathrm{O}_{3}$, (b) $\mathrm{ZnO}$ and (c) $\operatorname{In}_{2} \mathrm{O}_{3} / \mathrm{ZnO}$ heterojunction transistors fabricated via photonic curing. (d) Plot of $\left(\mathrm{I}_{\mathrm{DS}}\right)^{1 / 2}$ versus $\mathrm{V}_{\mathrm{G}}$ for all three devices from which the electron mobility and $V_{T}$ were extracted. (e) Representative output characteristics for a heterojunction transistor shown in (c). 

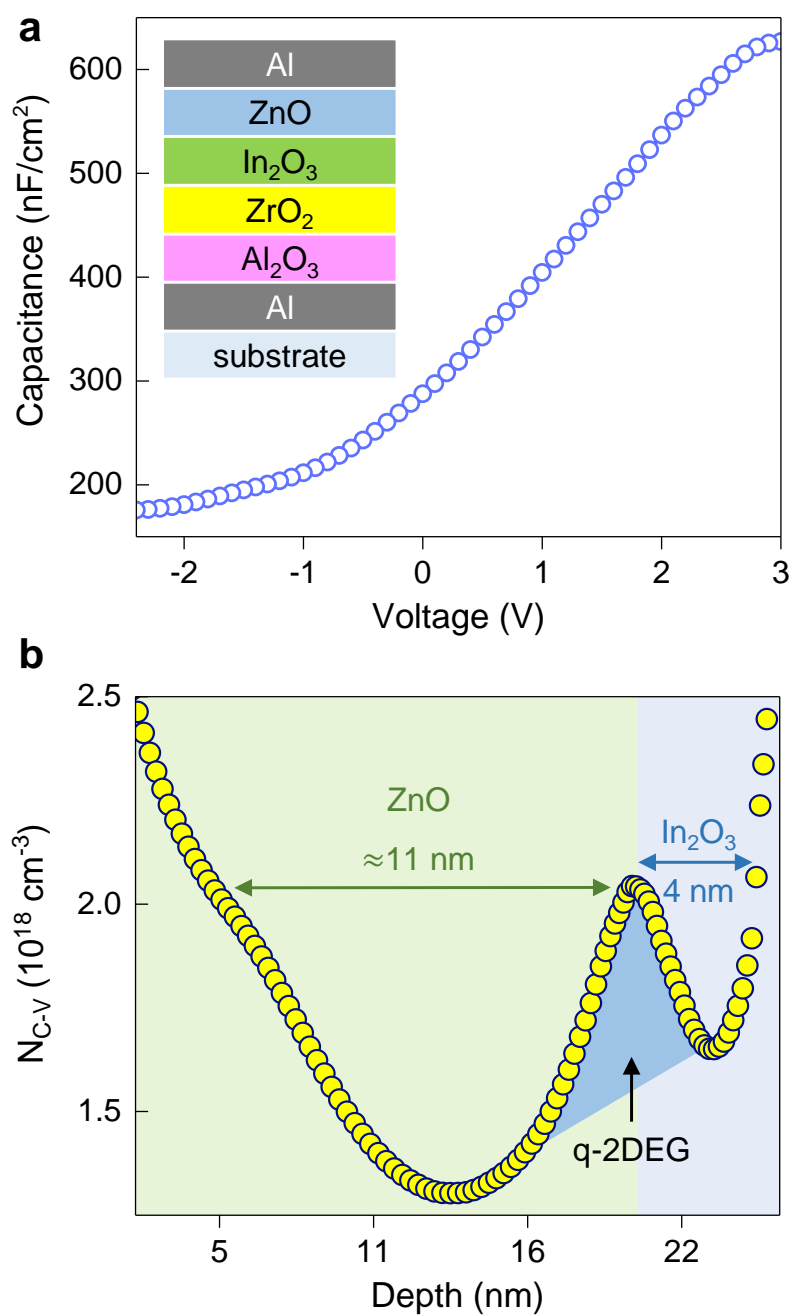

Figure 6. (a) Capacitance-Voltage measurement obtained from the metal-insulatorsemiconductor structure as indicated in the inset and (b) Free electron $\left(\mathrm{N}_{\mathrm{C}-\mathrm{v}}\right)$ profile as a function of depth from MIS structure. 

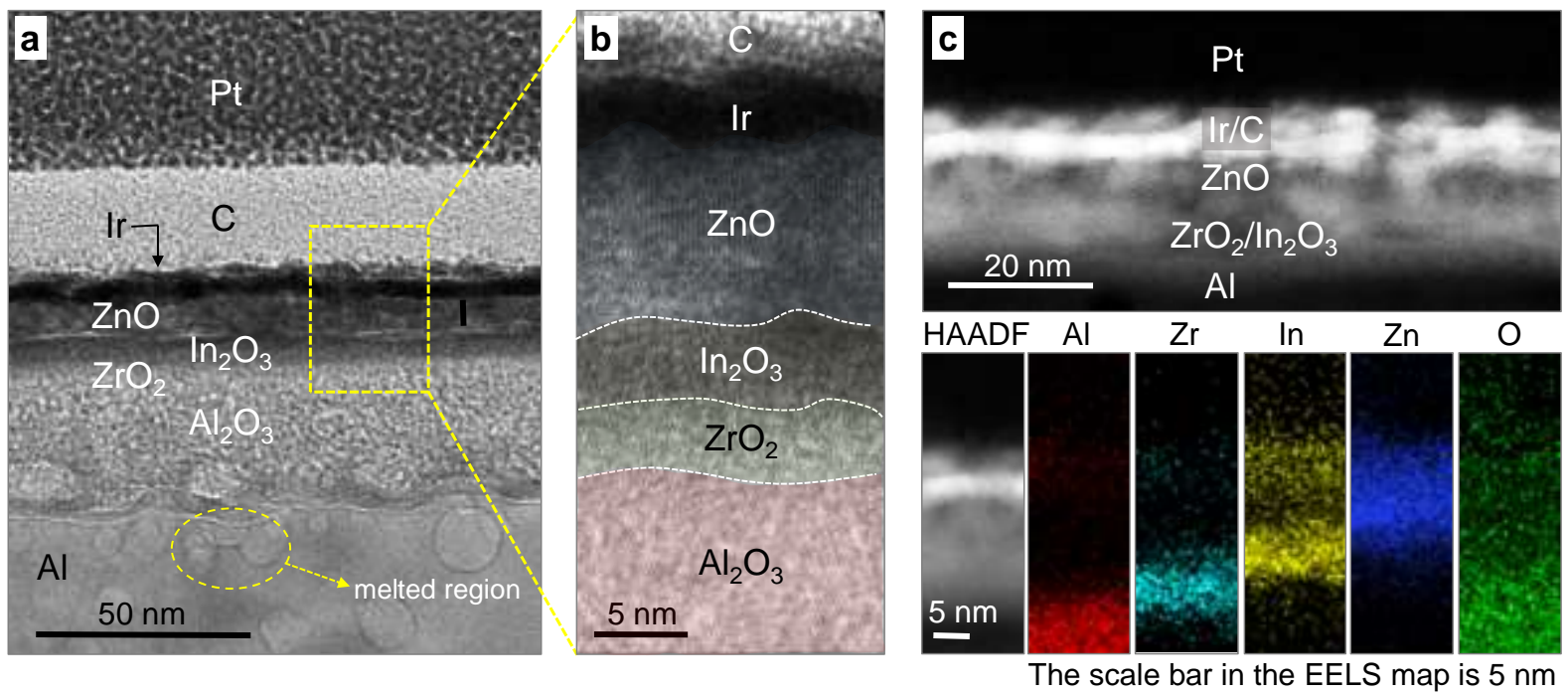

Figure 7. (a-b) Low to high magnification cross-sectional HRTEM. (c) STEM images of the complete metal oxide layer channel stack processed sequentially via spin-coating and photonic curing. The layers labelled Ir, C and Pt are applied during the TEM sample preparation for the sole purpose of imaging and don't have a functional role. (c) STEM cross-section and elemental distribution analysis throughout the layers measured with EELS. 


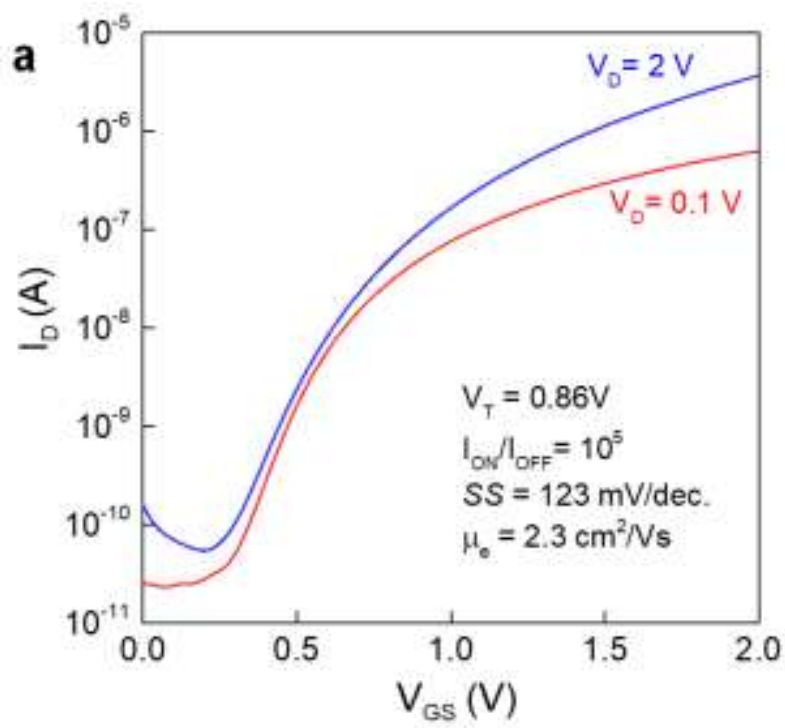

b

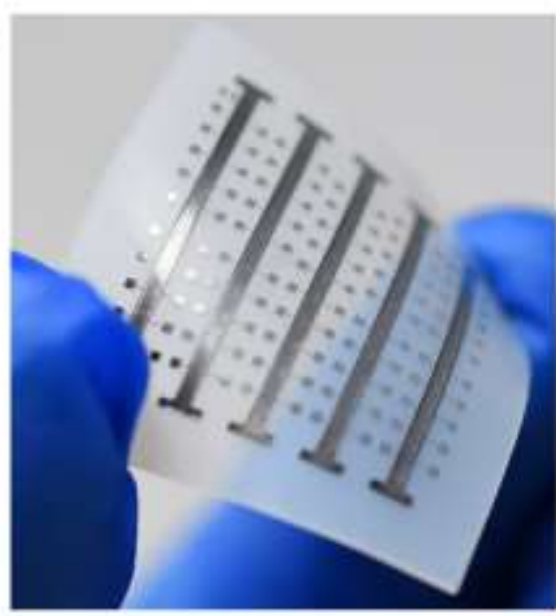

Figure 8. (a) Transfer characteristic of an $\mathrm{In}_{2} \mathrm{O}_{3} / \mathrm{ZnO}$ heterojunction TFT utilizing $\mathrm{Al}_{2} \mathrm{O}_{3} / \mathrm{ZrO}_{2}$ bilayer as the high- $k$ dielectric, photonically processed on PEN substrate. (b) Photograph of TFT arrays processed on a flexible PEN substrate. 


\section{ToC Text}

High electron mobility metal oxide transistors based on photonically-processed $\mathrm{Al}_{2} \mathrm{O}_{3} / \mathrm{ZrO}_{2}$ and $\mathrm{In}_{2} \mathrm{O}_{3} / \mathrm{ZnO}$ bilayers, acting as the high- $k$ dielectric and electron-transporting channel, respectively, are demonstrated. The photonic-based conversion process enables rapid manufacturing of metal oxide transistors while simultaneously minimizing the thermal budget making it compatible with temperature-sensitive substrate materials.

Keyword: Photonic curing, metal oxide semiconductors, metal oxide dielectrics, thin-film transistors, metal oxide heterojunctions

Emre Yarali, Hendrik Faber, Emre Yengel, Akmaral Seitkhan, Kalaivanan Loganathan, George T. Harrison, Begimai Adilbekova, Yuanbao Lin, Chun Ma, Yuliar Firdaus, Thomas D. Anthopoulos

\section{Low-Voltage Heterojunction Metal Oxide Transistors via Rapid Photonic Processing}

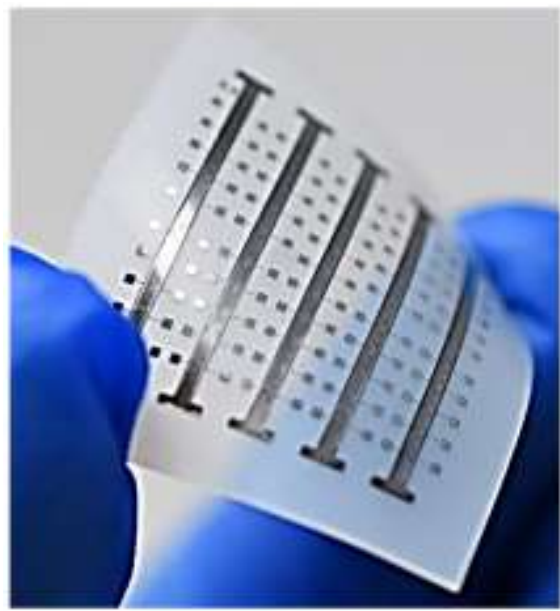


Copyright WILEY-VCH Verlag GmbH \& Co. KGaA, 69469 Weinheim, Germany, 2016.

\section{Supporting Information}

\section{Low-Voltage Heterojunction Metal Oxide Transistors via Rapid Photonic Processing}

Emre Yarali, Hendrik Faber, Emre Yengel, Akmaral Seitkhan, Kalaivanan Loganathan, George T. Harrison, Begimai Adilbekova, Yuanbao Lin, Chun Ma, Yuliar Firdaus, Thomas D. Anthopoulos*

Table S1. The qualitative assessment of $\mathrm{Al}$ ablation in combination with the precursor concentration and aluminum thickness during the fabrication of the $\mathrm{Al}_{2} \mathrm{O}_{3}$ layer.

\begin{tabular}{lcc}
$\begin{array}{l}\text { Thickness of Al electrode } \\
(\mathrm{nm})\end{array}$ & $\begin{array}{c}\text { Concentration of } \mathrm{Al}\left(\mathrm{NO}_{3}\right)_{3} \cdot 9 \mathrm{H}_{2} \mathrm{O} \text { precursor } \\
\text { solution }(\mathrm{mg} / \mathrm{ml})\end{array}$ & $\begin{array}{c}\text { Ablation } \\
\text { rate }\end{array}$ \\
\hline 40 & 100 & Medium \\
100 & 100 & None \\
100 & 250 & High \\
\hline
\end{tabular}
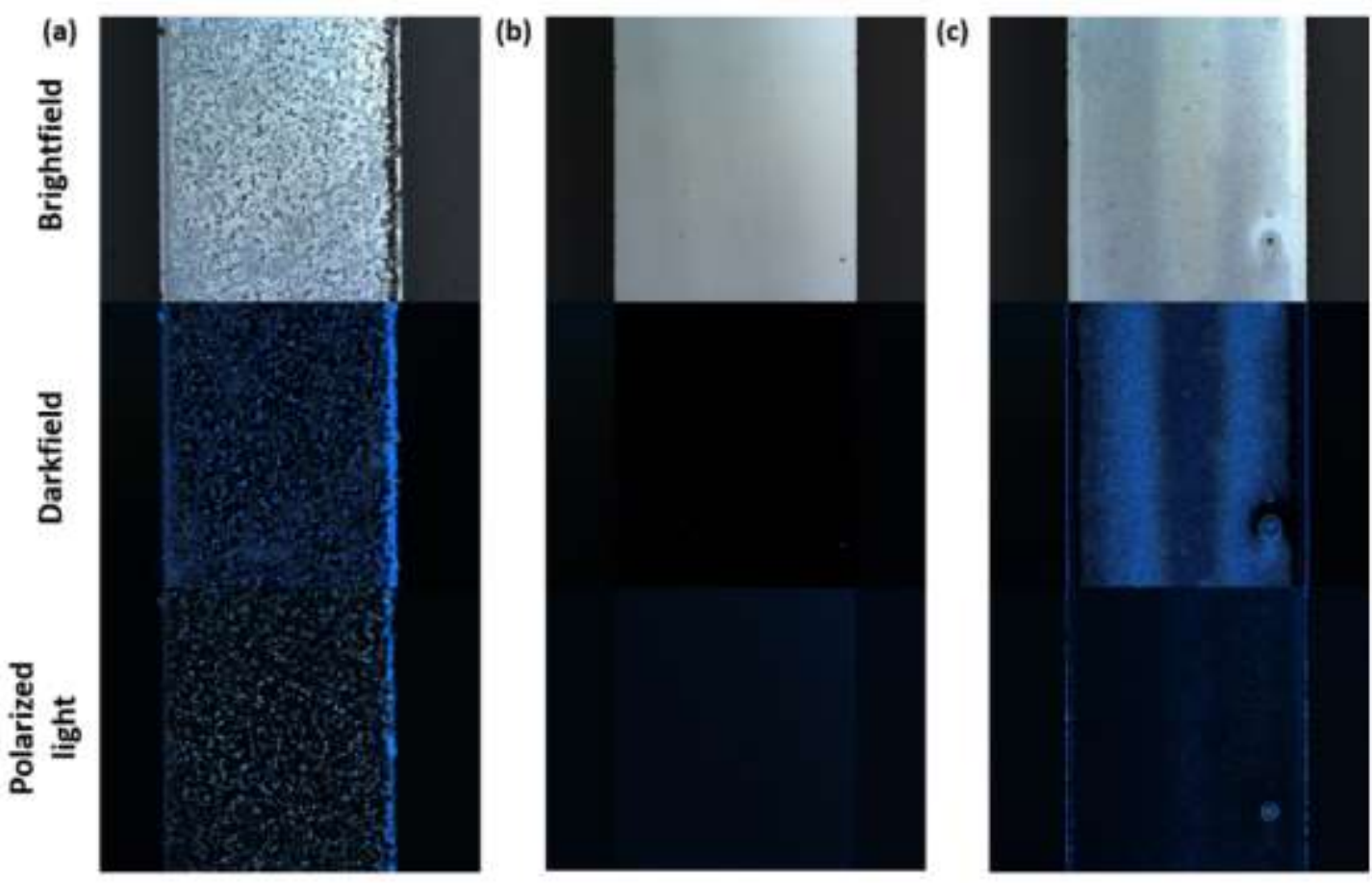

Figure S1. Optical microscopy images of the flashed metal electrodes with (a) $40 \mathrm{~nm}$ aluminum electrode with $100 \mathrm{mg} \mathrm{ml}^{-1} \mathrm{Al}\left(\mathrm{NO}_{3}\right)_{3} .9 \mathrm{H}_{2} \mathrm{O}$ concentration, (b) $100 \mathrm{~nm}$ aluminum electrode with $100 \mathrm{mg} \mathrm{ml}^{-1} \mathrm{Al}\left(\mathrm{NO}_{3}\right)_{3} .9 \mathrm{H}_{2} \mathrm{O}$ concentration and (c) $100 \mathrm{~nm}$ aluminum electrode with $250 \mathrm{mg}$ $\mathrm{ml}^{-1} \mathrm{Al}\left(\mathrm{NO}_{3}\right)_{3} .9 \mathrm{H}_{2} \mathrm{O}$ concentration. 


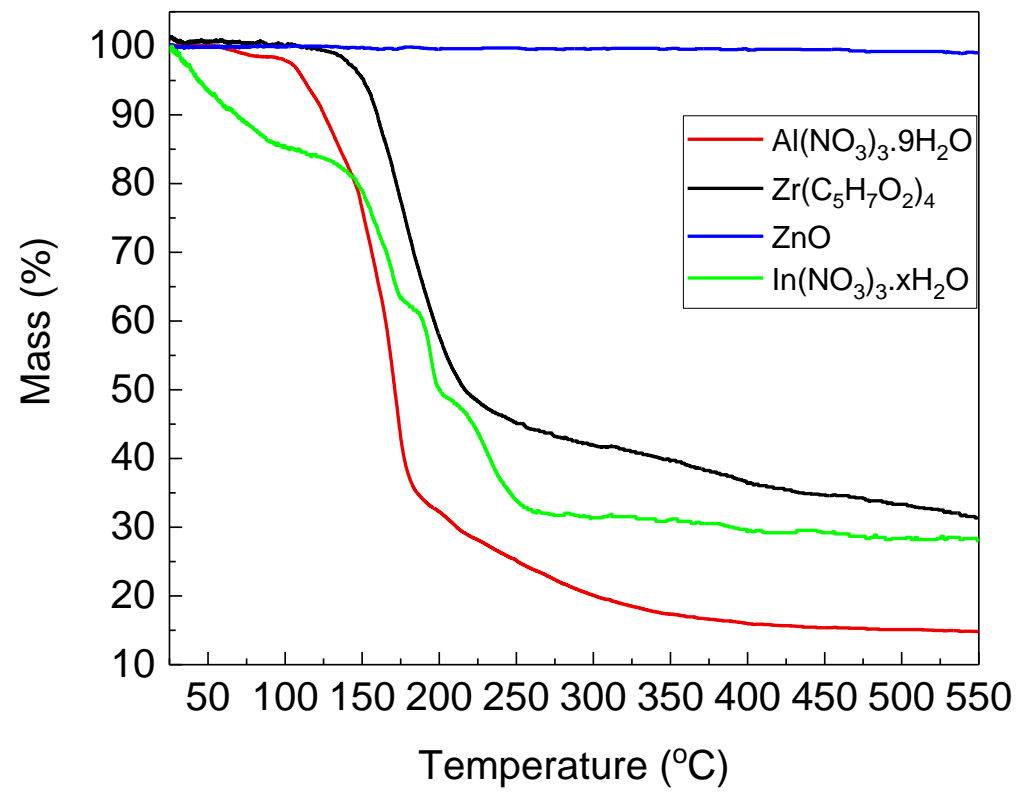

Figure S2. Thermogravimetric analysis of the metal precursors of $\mathrm{Al}\left(\mathrm{NO}_{3}\right)_{3} .9 \mathrm{H}_{2} \mathrm{O}$, $\mathrm{Zr}\left(\mathrm{C}_{5} \mathrm{H}_{7} \mathrm{O}_{2}\right)_{4}, \mathrm{ZnO}$ and $\ln \left(\mathrm{NO}_{3}\right)_{3} \cdot \mathrm{xH}_{2} \mathrm{O}$, respectively. 

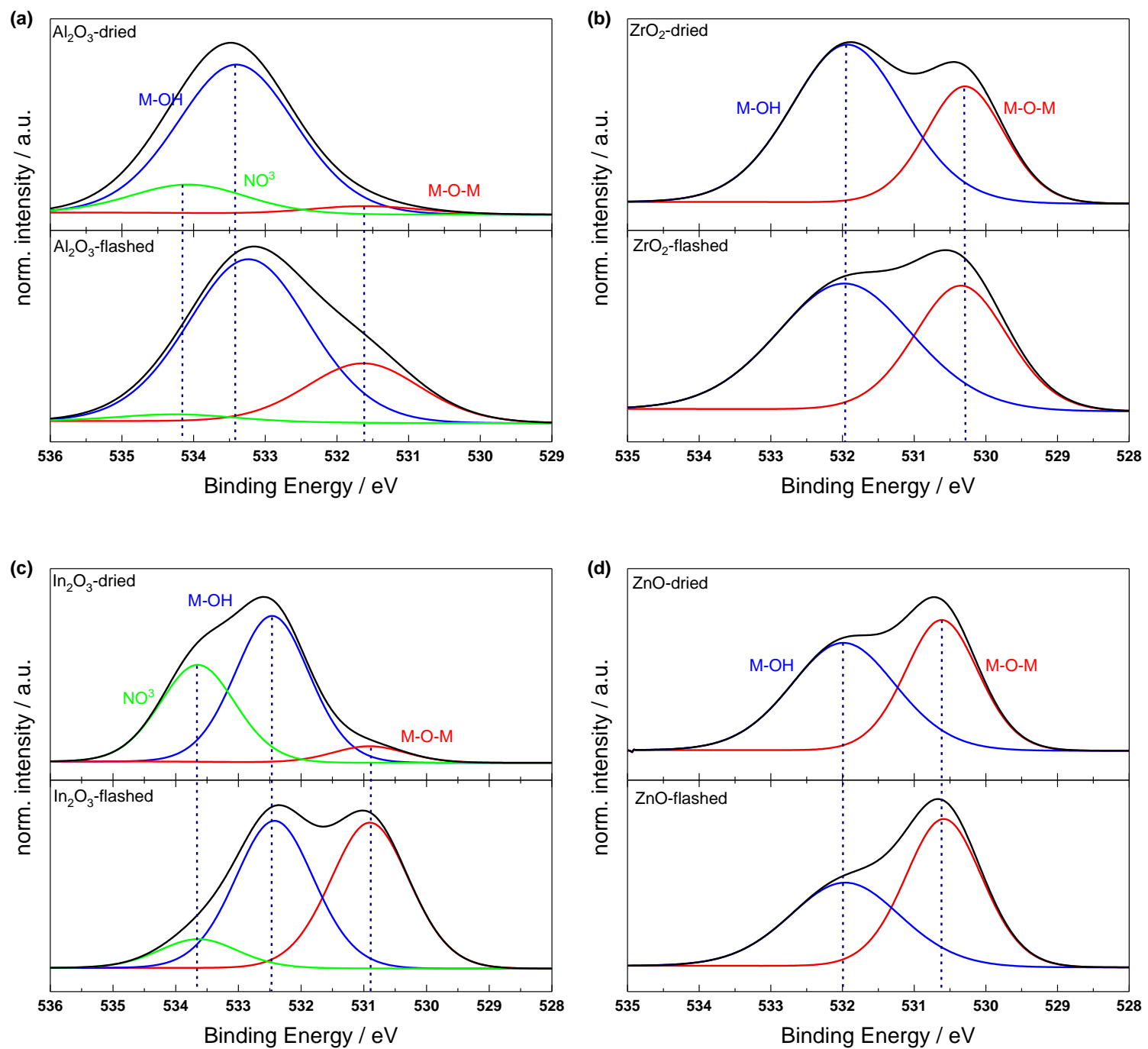

Figure S3. O 1s core level XPS spectra of (a) $\mathrm{Al}_{2} \mathrm{O}_{3}$, (b) $\mathrm{ZrO}_{2}$, (c) $\mathrm{In}_{2} \mathrm{O}_{3}$ and (d) $\mathrm{ZnO}$ before and after flashing. 
Table S2. Summary of the XPS results for the oxide layers before and after flash treatment.

\begin{tabular}{l|ccc|ccc}
\hline \multicolumn{5}{c|}{ Dried } & \multicolumn{3}{c}{ Flashed } \\
\hline Material & $\mathrm{M}-\mathrm{O} \%$ & $\mathrm{M}-\mathrm{OH} \%$ & $\mathrm{NO}_{3} \%$ & $\mathrm{M}-\mathrm{O} \%$ & $\mathrm{M}-\mathrm{OH} \%$ & $\mathrm{NO}_{3} \%$ \\
\hline $\mathrm{Al}_{2} \mathrm{O}_{3}$ & 3.04 & 81.93 & 15.03 & 24.85 & 72.25 & 2.8 \\
$\mathrm{ZrO}_{2}$ & 36.43 & 63.57 & - & 40.62 & 59.38 & - \\
$\mathrm{In}_{2} \mathrm{O}_{3}$ & 6.27 & 56.16 & 37.56 & 45.29 & 45.76 & 8.94 \\
$\mathrm{ZnO}$ & 48.3 & 51.2 & - & 57.9 & 42.1 & - \\
\hline
\end{tabular}

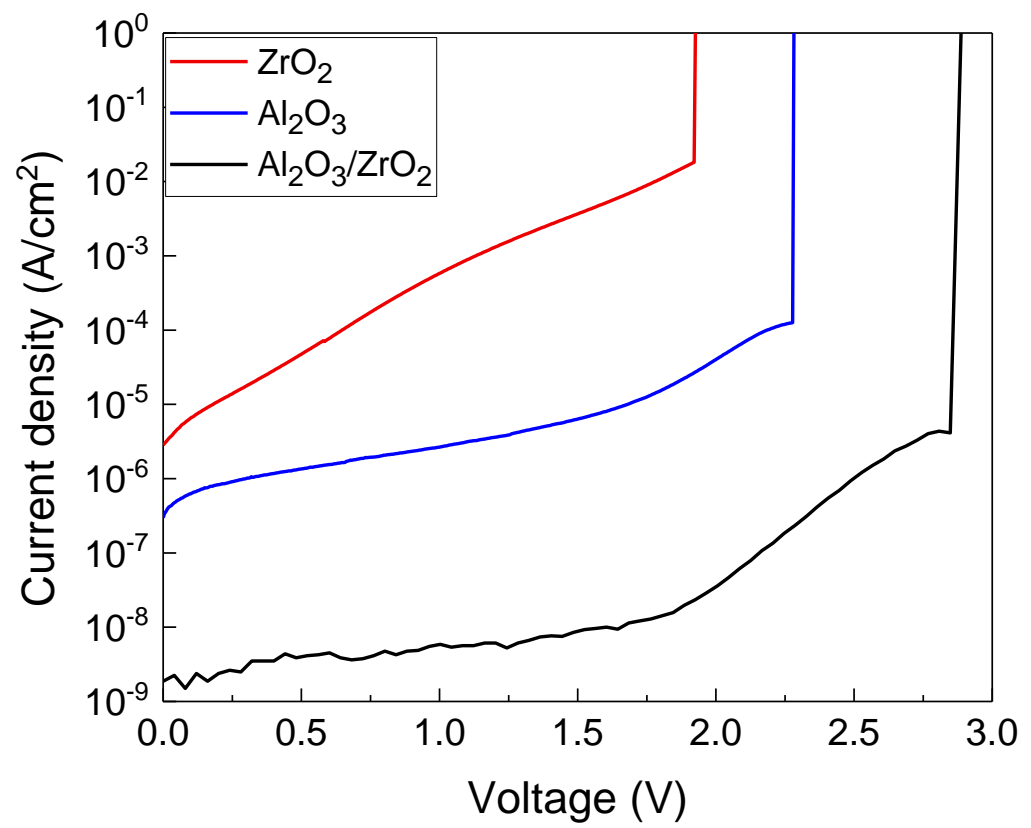

Figure S4. The leakage current densities of single layer of $\mathrm{Al}_{2} \mathrm{O}_{3}, \mathrm{ZrO}_{2}$ and bilayer $\mathrm{Al}_{2} \mathrm{O}_{3} / \mathrm{ZrO}_{2}$ recorded in metal/insulator/metal configuration. 

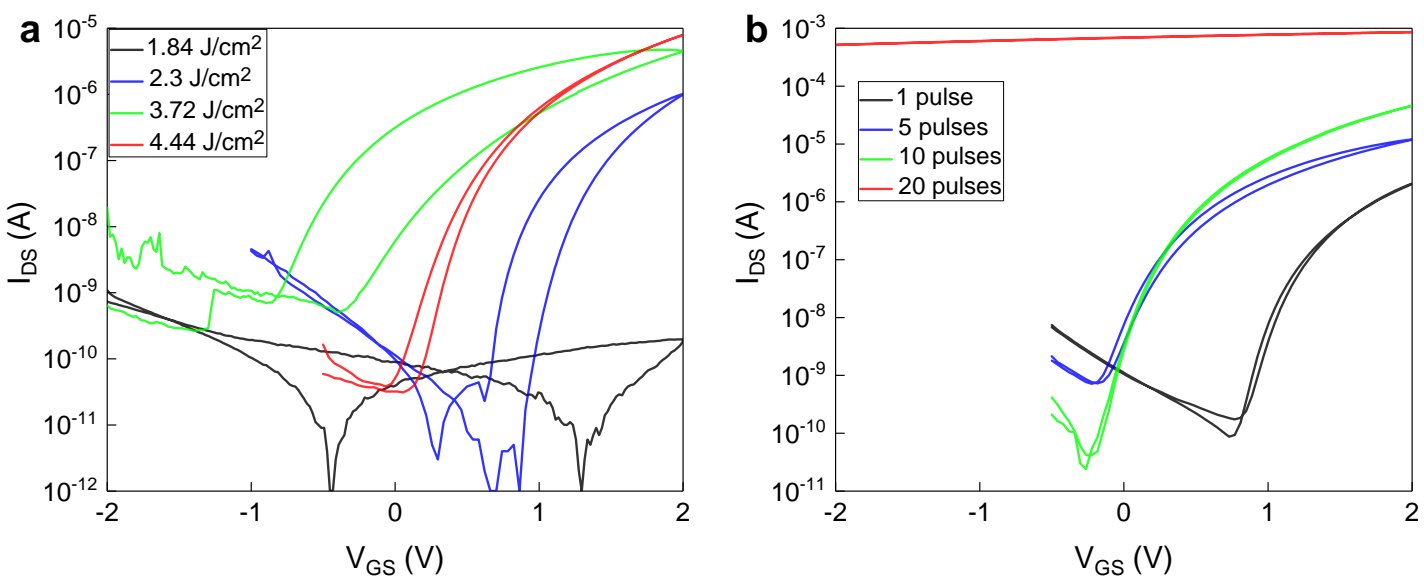

Figure S5. The transfer characteristics of (a) single layer In2O3 TFTs with different flash light densities and the same number of flashes of 30 pulses, (b) $\mathrm{In}_{2} \mathrm{O}_{3} / \mathrm{ZnO}$ heterojunction TFTs with the different number of flashes and same energy density of $4.44 \mathrm{~J} / \mathrm{cm}^{2}$.

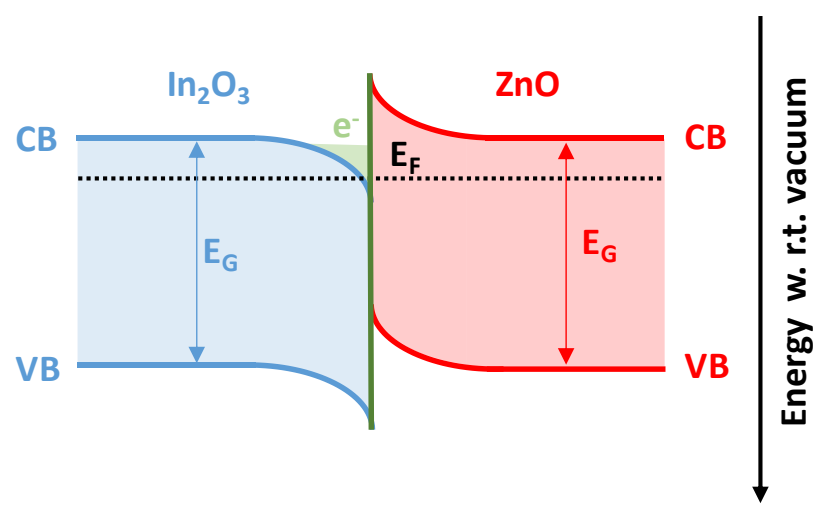

Figure S6. Energy band diagram of the $\mathrm{In}_{2} \mathrm{O}_{3} / \mathrm{ZnO}$ heterojunction. 


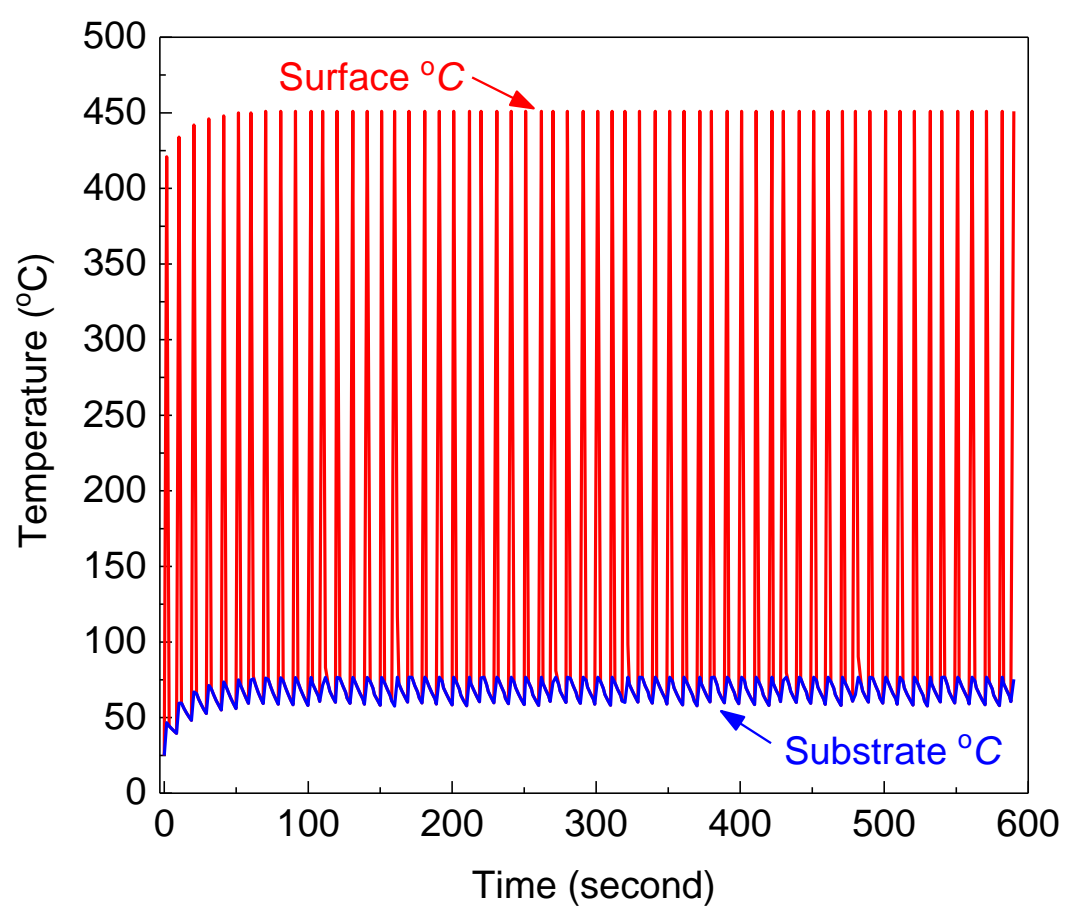

Figure S7. The simulation of the surface temperature of the aluminum electrode $(250 \mathrm{~nm})$ and of the PEN substrate temperature, generated with the SimPulse software, was used for the precursor conversion to form $\mathrm{Al}_{2} \mathrm{O}_{3} / \mathrm{ZrO}_{2} / \mathrm{In}_{2} \mathrm{O}_{3} / \mathrm{ZnO}$ layers with a fire rate of $0.1 \mathrm{~Hz}, 2000 \mu \mathrm{s}$ and $300 \mathrm{~V}, 60$ pulses. 